\title{
A high resolution model of linear trend in mass variations from DMT-2: added value of accounting for coloured noise in GRACE data
}

\author{
Hassan H. Farahani ${ }^{\mathrm{a}, *}$, Pavel Ditmar ${ }^{\mathrm{a}}$, Pedro Inácio ${ }^{\mathrm{a}}$, Olga Didova ${ }^{\mathrm{a}}$, Brian \\ Gunter $^{\mathrm{a}, \mathrm{b}}$, Roland Klees ${ }^{\mathrm{a}}$, Xiang Guo ${ }^{\mathrm{a}, \mathrm{c}}$, Jing Guo ${ }^{\mathrm{c}}$, Yu Sun ${ }^{\mathrm{a}}$, Xianglin \\ $\mathrm{Liu}^{\mathrm{a}, \mathrm{d}}$, Qile Zhao ${ }^{\mathrm{c}}$, Riccardo Riva ${ }^{\mathrm{a}}$ \\ ${ }^{a}$ Delft University of Technology, Stevinweg 1, 2628 CN, Delft, The Netherlands \\ ${ }^{b}$ Georgia Institute of Technology, 270 Ferst Dr. NW, Atlanta, GA 30332-0150, USA \\ ${ }^{c}$ GNSS Research Center, Wuhan University, 129 Luoyu Rd., Wuhan 430079, China \\ ${ }^{d}$ Fugro Intersite B.V., Dillenburgsingel 69, 2263 HW, Leidschendam, The Netherlands
}

\section{Abstract}

We present a high resolution model of the linear trend in the Earth's mass variations based on DMT-2 (Delft Mass Transport model, release 2). DMT-2 was produced primarily from K-Band Ranging (KBR) data of the Gravity Recovery And Climate Experiment (GRACE). It comprises a time series of monthly solutions complete to spherical harmonic degree 120. A novel feature in its production was the accurate computation and incorporation of stochastic properties of coloured noise when processing KBR data. The unconstrained DMT-2 monthly solutions are used to estimate the linear trend together with a bias, as well as annual and semi-annual sinusoidal terms. The linear term is further processed with an anisotropic Wiener filter, which uses full noise and signal covariance matrices. Given the fact that noise in an unconstrained model of the trend is reduced substantially as compared

\footnotetext{
* Corresponding author

Email address: h.hashemi@tudelft.nl (Hassan H. Farahani )
} 
to monthly solutions, the Wiener filter associated with the trend is much less aggressive compared to a Wiener filter applied to monthly solutions. Consequently, the trend estimate shows an enhanced spatial resolution. It allows signals in relatively small water bodies, such as Aral sea and Ladoga lake, to be detected. Over the ice sheets, it allows for a clear identification of signals associated with some outlet glaciers or their groups. We compare the obtained trend estimate with the ones from the CSR-RL05 model using (i) the same approach based on monthly noise covariance matrices and (ii) a commonly-used approach based on the DDK-filtered monthly solutions. We use satellite altimetry data as independent control data. The comparison demonstrates a high spatial resolution of the DMT-2 linear trend. We link this to the usage of high-accuracy monthly noise covariance matrices, which is due to an accurate computation and incorporation of coloured noise when processing KBR data. A preliminary comparison of the linear trend based on DMT-2 with that computed from GSFC_global_mascons_v01 reveals, among other, a high concentration of the signal along the coast for both models in areas like the ice sheets, Gulf of Alaska, and Iceland.

Keywords: Time varying gravity field, GRACE, KBR, DMT-2, Coloured noise

\section{1. Introduction}

2 Temporal variations of the Earth's gravity field at various spatial scales 3 are known to be caused by mass re-distribution due to megathrust earth4 quakes (e.g., Han et al., 2006, 2011), accumulation and depletion of conti5 nental water stocks (e.g., Wahr et al., 1998; Swenson et al., 2003; Klees et 

7 et al., 2014), ice mass losses in the polar areas (e.g., Luthcke et al., 2006;

al., 2007, 2008a), postglacial rebound (e.g., van der Wal et al., 2008; Gunter Wouters et al., 2008; Baur and Sneeuw, 2011; Rignot and Mouginot, 2012; Siemes et al., 2013), and the subsequent sea level rise (e.g., Bamber et al., 2009). The primary tool to observe the large-scale mass variations is currently the Gravity Recovery And Climate Experiment (GRACE) satellite mission, which has been operational since March 2002 (Tapley et al., 2004a,b). The K-Band Ranging (KBR) data, collected by this mission, in conjunction with its other measurements, i.e., GPS (Global Positioning System), attitude, and accelerometer data, are processed by different research centres, and various models of time-variations are computed (e.g., Bettadpur, 2007, 2012; Flechtner, 2007; Watkins and Yuan, 2007, 2012; Kurtenbach et al., 2009; Dahle et al., 2012; Bruinsma et al., 2010; Liu, 2008; Liu et al., 2010; Mayer-Gürr et al., 2010a,b, 2014; Meyer et al., 2012; Chen et al., 2015). The majority of models make use of spherical harmonics (e.g., Heiskanen and Moritz, 1967) and are complete to degree 60 - 120, which corresponds to spatial scales larger than $165-330 \mathrm{~km}$ (half-wavelength). Some other models, e.g., those produced by Luthcke et al. (2013) and Watkins et al. (2015), are based on mass concentration blocks, i.e., so-called mascons parametrization. They are vastly believed to improve the spatial resolution further as compared to spherical harmonic models of the mass transport (Watkins et al., 2015). The temporal sampling of GRACE-based models is typically one month.

Recently, Delft University of Technology, in collaboration with the GNSS Research Centre of Wuhan University, has compiled and released a new spherical harmonic model entitled DMT-2: Delft Mass Transport model, release 
2 (Farahani, 2013). Similar to its predecessor DMT-1 (Liu, 2008; Liu et al., 2010), the new model consists of a time series of monthly solutions complete to degree 120. Both unconstrained and constrained (i.e., filtered) solutions are available. In the latter case, an anisotropic Wiener-type filter developed by Klees et al. (2008b) is applied to suppress noise, which is primarily caused by an anisotropic sensitivity of the KBR data and manifests itself in the form of pronounced along-track artifacts, i.e., the well-known "stripes". The filter is based on the full signal and noise covariance matrices. It is designed as a mean square error filter of monthly mass re-distribution. It is a spatially-varying filter, meaning that the smoothing is minimal in areas where signal is strong (i.e., the lower the noise, the less smoothing, and vice versa). Unlike in DMT-1, degree-1 coefficients are restored in the DMT-2 monthly solutions using a modified version of the approach of Swenson et al. (2008), which is described in (Sun et al., 2016). A novel feature of the methodology designed to produce DMT-2 is an accurate computation and incorporation of stochastic properties of coloured noise when processing KBR data. This leads to an accurate computation of noise covariance matrices, which enter Wiener filters. With this manuscript, we use DMT-2 to compute new models of the long-term linear trend in mass variations, which vary in terms of maximum spherical harmonic degree. To that end, we follow the methodology developed by Siemes et al. (2013). It is, in essence, a further development of the filtering idea of Klees et al. (2008b). It is realized by a design and application of an anisotropic Wiener-type filter to the linear trend obtained from unconstrained monthly solutions. That is, it is designed as a mean square error filter of linear trends in mass re-distribution. For com- 
parison, we additionally produce a filtered linear trend from the CSR-RL05 monthly solutions (Bettadpur, 2012) and their noise covariance matrices, using the same methodology. In addition, we compute the linear trend in line with a commonly-used approach, i.e., using monthly solutions subject to DDK de-correlating non-isotropic filtering (Kusche, 2007; Kusche et al., 2009). We assess the models of the linear trend with satellite altimetry data. The comparison allows us to study the added value of the applied Wiener filter. It additionally allows for an analysis of the added value of accounting for coloured noise when processing KBR data, which is currently done in the production of only a few spherical harmonic time-varying gravity field models, namely, DMT-2 and those produced in line with Mayer-Gürr (2006) and Mayer-Gürr et al. (2010a). Finally, we make a preliminary comparison of the linear trend model based on DMT-2 with one produced with a latest mascon implementation, namely, GSFC_global_mascons_v01 (Luthcke et al., 2013).

The manuscript is outlined as follows. Section 2 (in conjunction with Appendix A) describes the computation of DMT-2 monthly unconstrained solutions. In Section 3, we compute and assess the model of the linear trend. A brief description of how it is computed from the monthly solutions is also presented there. Finally, in Section 4, we conclude by emphasizing the main findings and identifying topics for future research.

\section{DMT-2}

DMT-2 consists of monthly gravity field solutions spanning the time interval February 2003 - December 2011. Three months (June 2003, January 
2011, and June 2011) are excluded due to a complete or a partial lack of GRACE data. The solutions consist of residual spherical harmonic coefficients with respect to the static gravity field model DGM-1S: Delft Gravity Model, release 1, satellite-only (Farahani et al., 2013a,b). The coefficients were estimated by a stand-alone inversion of KBR data. The unconstrained procedure consisted of two steps: (1) transforming KBR data into residual gravity data (cf. Appendix A) with respect to the a priori model; and (2) inverting these residuals into residual spherical harmonic coefficients using the least-squares adjustment in a statistically optimal manner. The first step was done mostly in the same way as in the case of DMT-1. For the completeness, we briefly describe it in Appendix A. A novel element of the second step was an accurate computation and parameterization of coloured noise in KBR data, which is described below.

Residual range combinations are contaminated by frequency-dependent (i.e., coloured) noise (e.g., Liu et al., 2010). To account for this, frequencydependent data weighting (e.g., Klees et al., 2003; Klees and Ditmar, 2004) was used. This ensures a statistically optimal inversion of the residual data, provided that (i) an accurate realization of their noise is obtained and (ii) the stochastic properties of the noise are modeled properly. To realize the latter, Auto-Regressive Moving-Average (ARMA) noise models, whose Power Spectral Densities (PSDs) best fit PSDs of the noise, were built (Klees and Broersen, 2002; Klees et al., 2003). Noise realizations were produced iteratively as described in the following. The residual data themselves were assumed to be initial noise realizations. This allowed initial ARMA models to be produced, which resulted in preliminary monthly gravity field solu- 


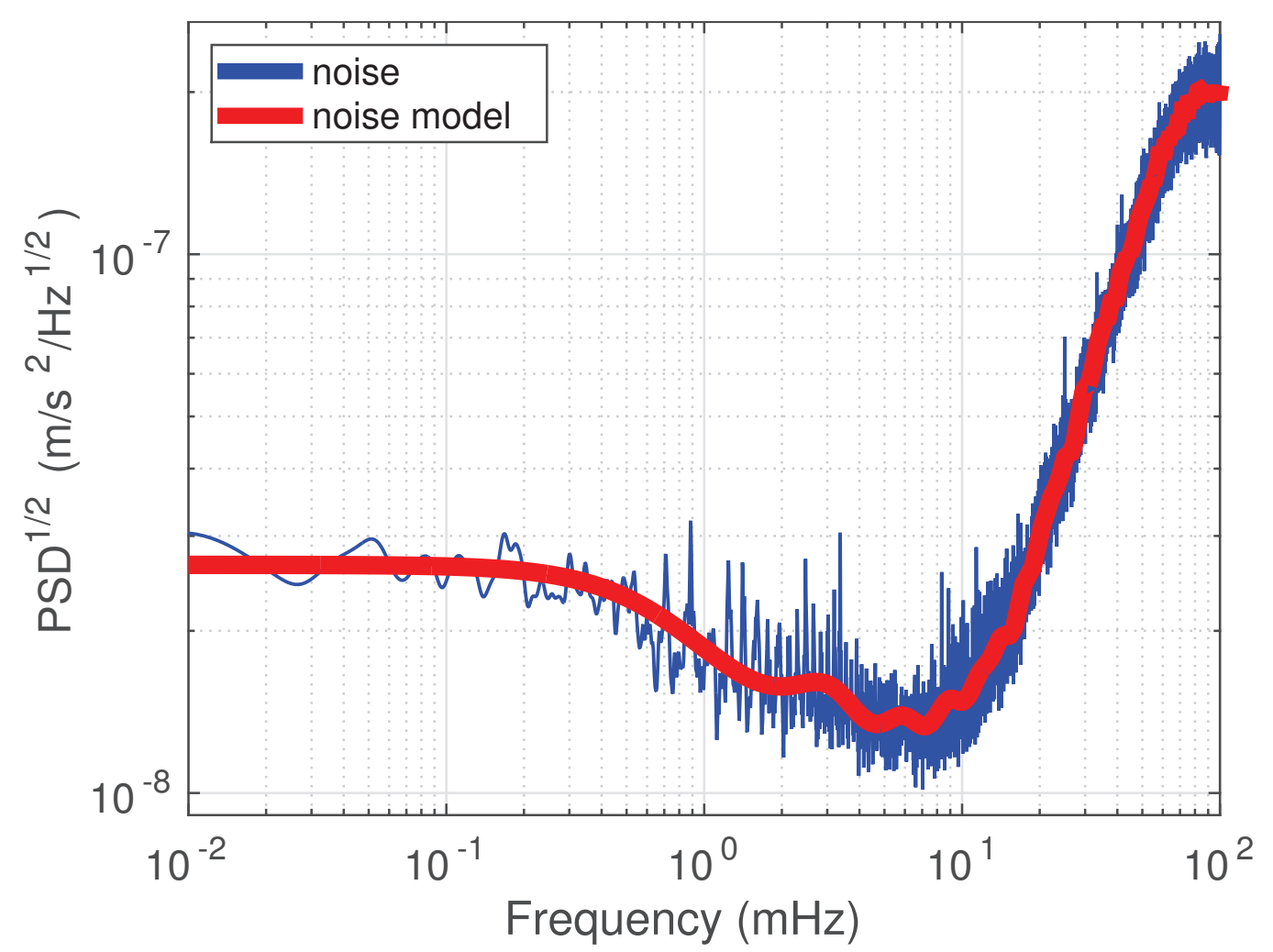

Figure 1: The $\mathrm{PSD}^{\frac{1}{2}}$ of noise and of stochastic model of noise in residual range combinations for July 2006.

tions. The corresponding sets of a posteriori residuals were used as improved realizations of noise. No additional iterations of this kind were necessary, as further changes in the estimated noise properties were found to be negligible. As an example, Fig. 1 shows the $\mathrm{PSD}^{\frac{1}{2}}$ of noise in residual range combinations in July 2006 together with its best-fitting ARMA model, which is in this instance an Auto-Regressive (AR) one of order 79. Such a model of noise was built for each month individually. In this way, gradual changes in the noise characteristics were captured. We found that those changes are particularly pronounced in the frequency range $0.5-10 \mathrm{mHz}(3-54$ cycles 


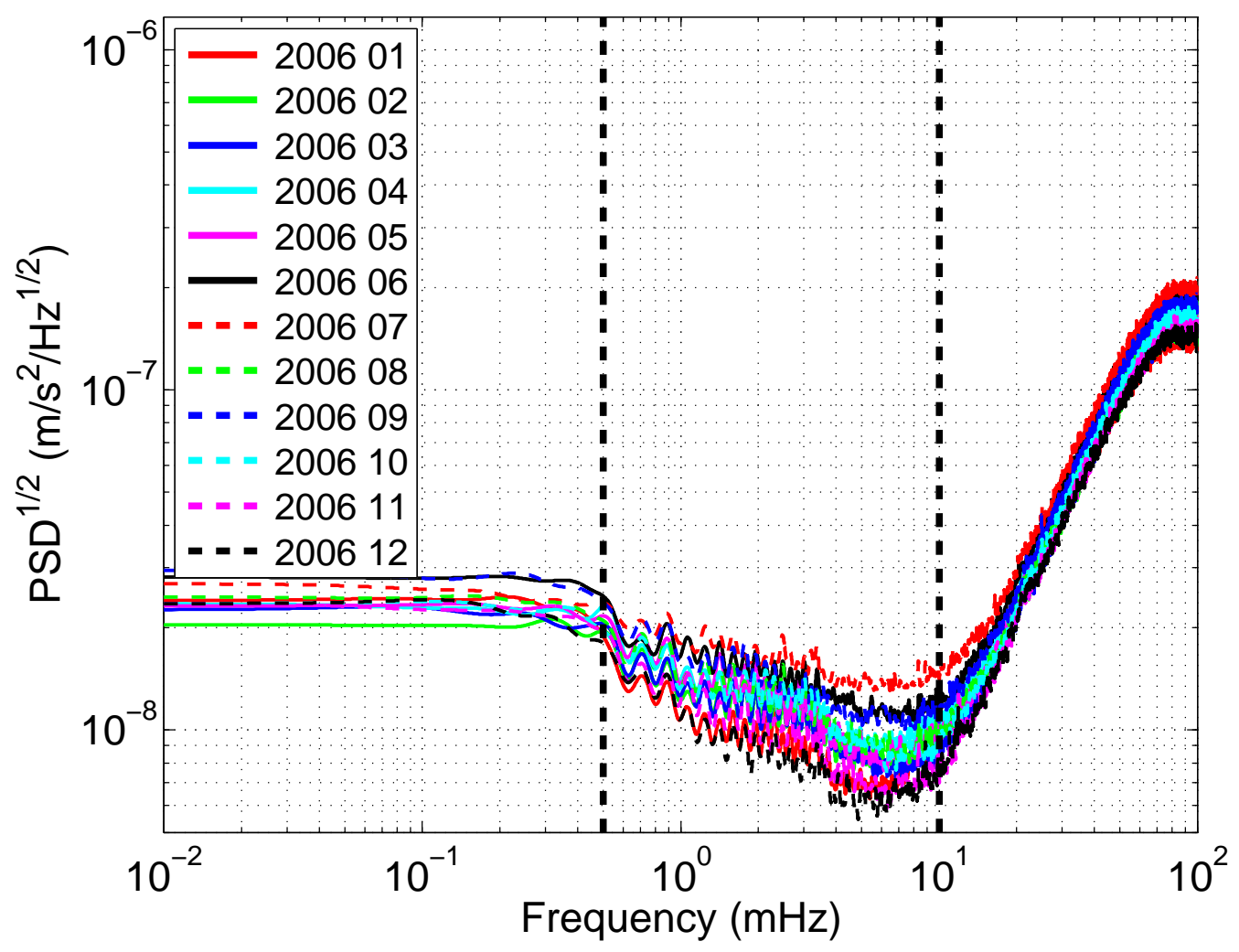

Figure 2: The noise $\mathrm{PSD}^{\frac{1}{2}} \mathrm{~S}$ in the residual range combinations in 2006. The vertical lines mark the frequencies 3 and $54 \mathrm{cpr}$. 


\section{Linear trend}

We begin with a brief description of the methodology followed to compute different variants of the linear trend (Section 3.1). The comparison of the results are provided in Section 3.2.

\subsection{Methodology}

We compute the constrained linear trend in line with the methodology developed by Siemes et al. (2013). To that end, we first compute an unconstrained model of the linear trend, together with a bias, as well as annual and semi-annual (co-) sinusoidal terms, from the unconstrained DMT-2 monthly solutions. Furthermore, we propagate noise covariance matrices of the unconstrained monthly solutions onto the linear trend noise covariance matrix. In doing so, so-called formal noise covariance matrices are used, i.e., those obtained from the estimation process without any correction or scaling. Finally, we compute the constrained model of the linear trend with the Wiener-type filter of Klees et al. (2008a)

$$
\mathbf{F}=\left\{\left(\mathbf{C}_{\hat{\mathbf{x}}}\right)^{-1}+\mathbf{D}^{-1}\right\}^{-1}\left(\mathbf{C}_{\hat{\mathbf{x}}}\right)^{-1},
$$

or equivalently

$$
\mathbf{F}=\mathbf{D}\left\{\mathbf{C}_{\hat{\mathbf{x}}}+\mathbf{D}\right\}^{-1},
$$

based on the full signal covariance matrix $\mathbf{D}$ and the full noise covariance matrix $\mathbf{C}_{\hat{\mathbf{x}}}$ of the linear trend. To compute $\mathbf{D}$ as reliably as possible, the time span for which the linear trend is to be estimated is divided into multiple intervals of the same length. This allows us to obtain multiple intermediate samples of the linear trend, from which an estimate of $\mathbf{D}$ can be obtained. 
Then, this estimate is improved iteratively. It is not subjected to any scaling or other corrections. Details are documented by Siemes et al. (2013). This way of computing the linear trend is motivated by the fact that noise in an unconstrained model of the linear trend is substantially reduced as compared to that in unconstrained monthly solutions. Thus, a Wiener-type filter tailored for the linear trend is much less aggressive than those associated with monthly solutions. Therefore, the trend produced in this way as opposed to that derived from constrained monthly solutions shows a higher spatial resolution (Siemes et al., 2013).

For comparison, we produce another constrained estimate of the linear trend using CSR-RL05 monthly solutions and their noise covariance matrices with the same methodology. The CSR-RL05 solutions are complete to degree 96, whereas DMT-2 solutions extend to degree 120. To ensure a fair comparison of them, we additionally compute the linear trend in the case of DMT-2 to degree 96. This requires computing clones of DMT-2 monthly unconstrained solutions to degree 96 . This does not necessarily require a reprocessing of KBR data from scratch. These clones can be easily computed using DMT-2 unconstrained solutions and their noise covariance matrices. Technical aspects of these computations are provided in Appendix B. For brevity, we hereafter refer to the trend estimated from DMT-2 unconstrained solutions complete to degree 96 as "DMT-2-DEG-96". Moreover, we compute models of the linear trend following the standard approach by first filtering the monthly solutions before the linear trend is estimated. To that end, we use CSR-RL05 monthly solutions subsequent to the DDK-5 and DDK-8 decorrelating non-isotropic filter (Kusche, 2007; Kusche et al., 2009). These 
estimates of the linear trend are, hereafter, referred to as "CSR-RL05-DDK5" and "CSR-RL05-DDK-8", respectively. Their computation includes a co-estimation of a bias, as well as annual and semi-annual (co-) sinusoidal terms to be consistent with other estimates noted earlier. Given the fact that the DDK-8 filter in terms of the smoothing radius of an approximately equivalent Gaussian filter is smaller than the DDK-5 one (Kusche et al., 2009), an analysis of the results associated with these two filters allows the effect of the corresponding Gaussian smoothing radius to be studied in the side line.

\subsection{Results}

In this manuscript, we produce models of the linear trend in the time interval February 2003 - December 2008. This time interval is chosen since we compare results against, among others, surface elevations from ICESat laser altimeter data, which are available only to October 2009. Furthermore, a computation of GRACE-based linear trends with the Wiener filter of Siemes et al. (2013) requires dividing the time interval into multiple two-year segments. Hence, currently we can compute the linear trend for either February 2003 - December 2008 or February 2003 - December 2010. Only the former time interval allows for a consistent comparison of our results with those based on ICESat data.

In this section, we primarily focus on a comparison of the spherical harmonic models mentioned earlier, namely, DMT-2, "DMT-2-DEG-96", CSRRL05, "CSR-RL05-DDK-5", and "CSR-RL05-DDK-8" (section 3.2.1). However, to provide an idea on how spherical harmonic and mascons parametrizations compare, we close this section with a comparison between linear trends based on DMT-2 and GSFC_global_mascons_v01 (section 3.2.2). The com- 
191

192

193

194

195

196

197 heights (EWH). 


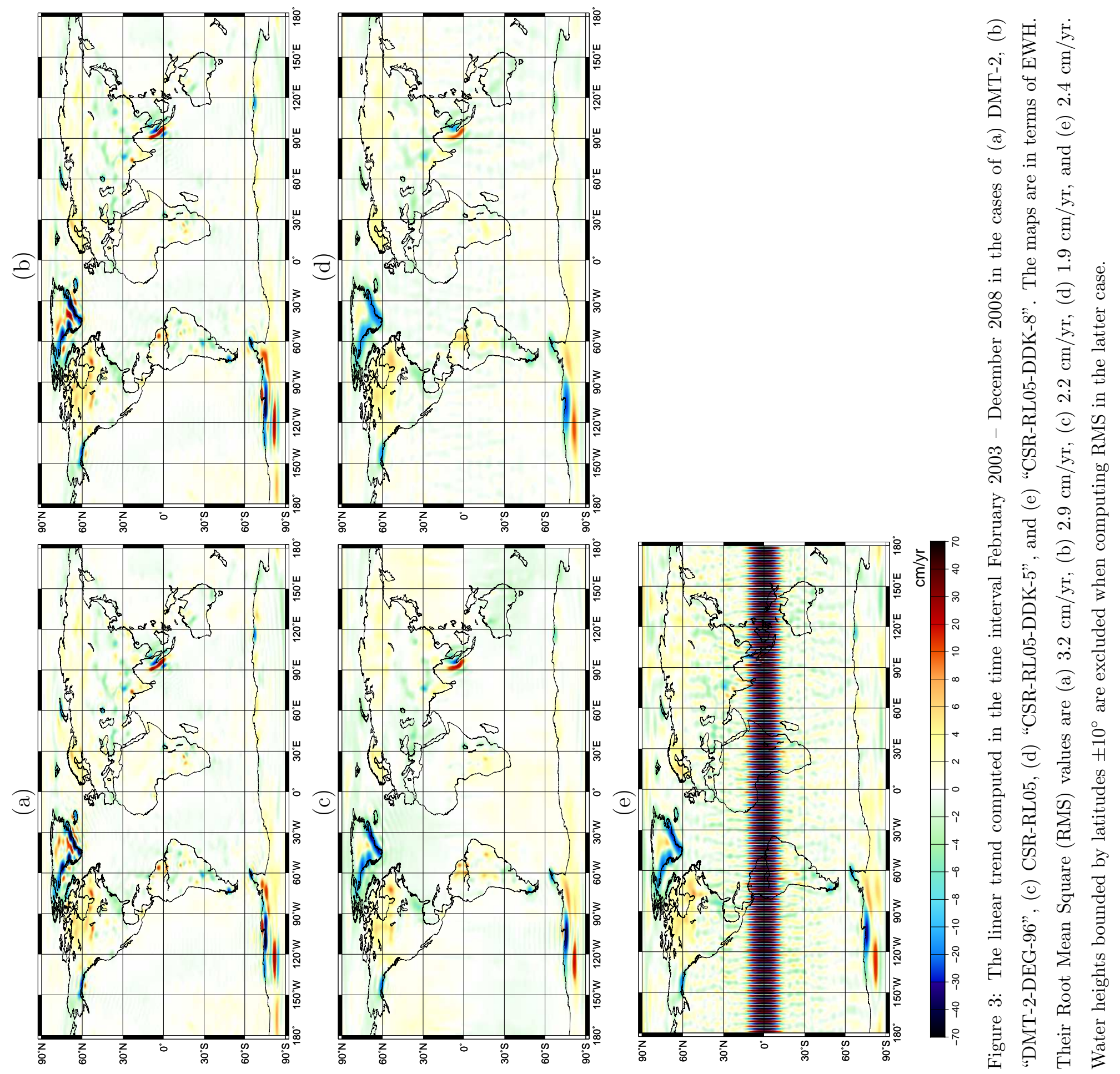


The improved spatial resolution of Wiener filter estimates DMT-2, "DMT2-DEG-96", and CSR-RL05 compared to "CSR-RL05-DDK-5" is clearly visible, particularly, in Greenland, Antarctica, and Gulf of Alaska. Moreover, the former two trend estimates show much more power compared to "CSRRL05-DDK-5". This is obvious when looking at the Root Mean Square (RMS) EWH, which are provided in the caption of Fig. 3. The situation is different when comparing the linear trend Wiener filter estimates with "CSRRL05-DDK-8". The latter also reveals an improved spatial resolution and increased signal power. However, "CSR-RL05-DDK-8" compromises results with stripes in equatorial areas bounded by latitudes $\pm 10^{\circ}$ (Fig. 3e). This is the reason why those areas were excluded when calculating the RMS EWH in case of "CSR-RL05-DDK-8". These results indicate that when computing the linear trend from DDK-filtered monthly solutions, the filter variant, i.e., the corresponding Gaussian smoothing radius, needs to be chosen in line with the geographical area in interest. Further evidences to support this statement will be provided later.

A zoom-in at selected locations provides further insight into the differences between the five linear trend estimates. To that end, we focus on two selected lakes (Section 3.2.1.1) and on the ice sheets (Section 3.2.1.2).

\subsubsection{Lakes}

We select two relatively small water bodies: Ladoga lake and the Aral sea. The five estimates of the linear trend over these areas are respectively presented in Figs. 4 and 5. The trends produced from DMT-2 and its clone to degree 96 clearly demonstrate a gain of water mass in the Ladoga lake and a 
(a)

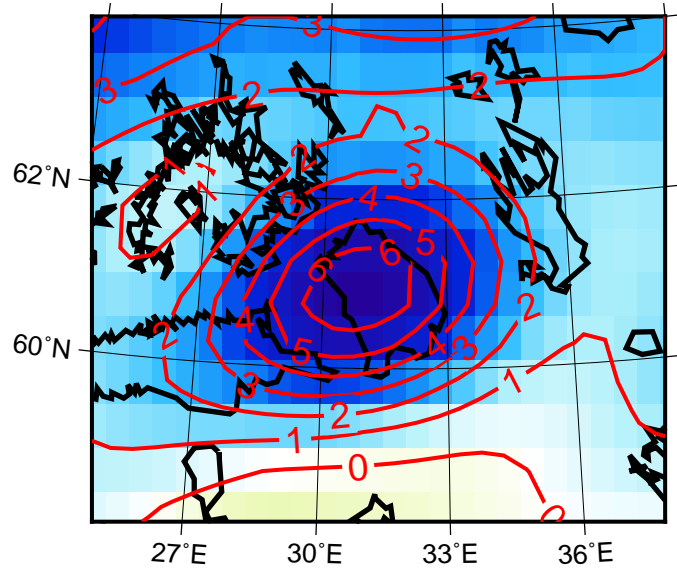

(c)

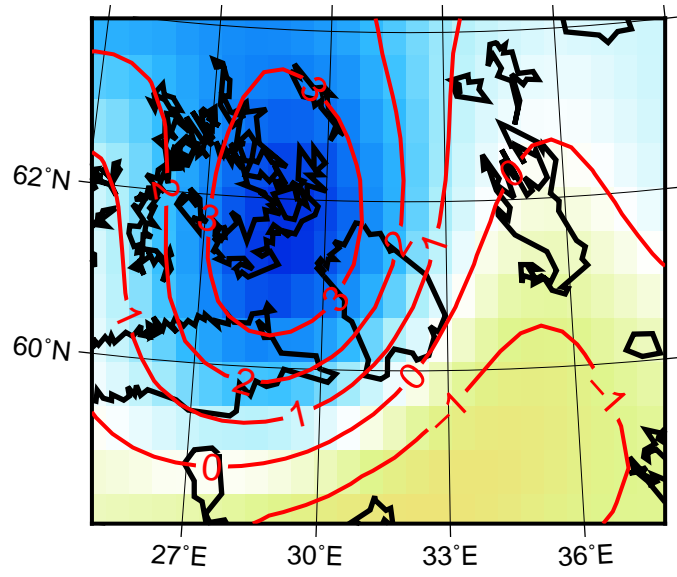

(e)

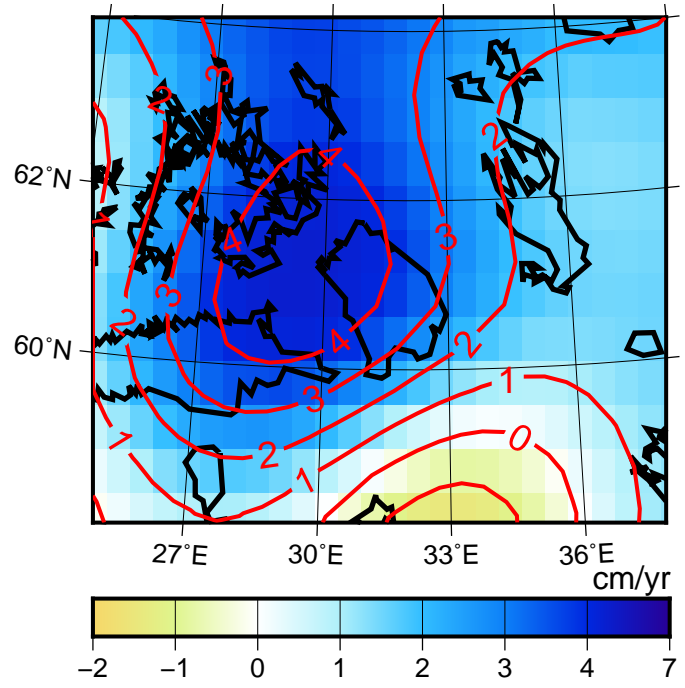

(b)

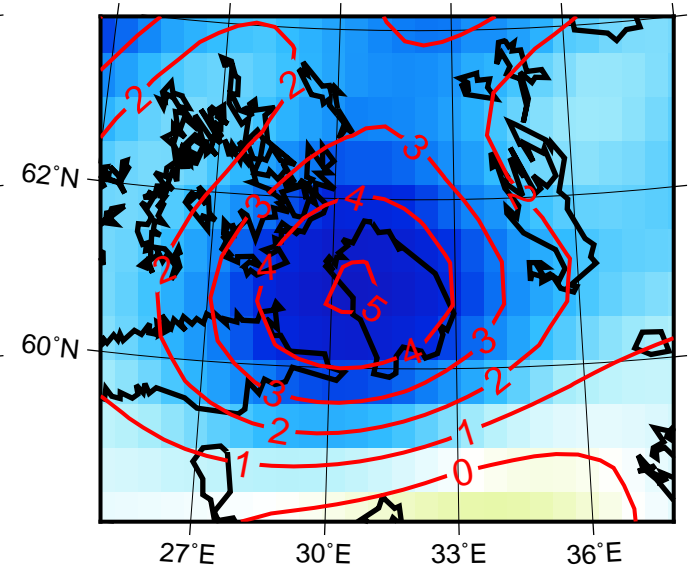

(d)

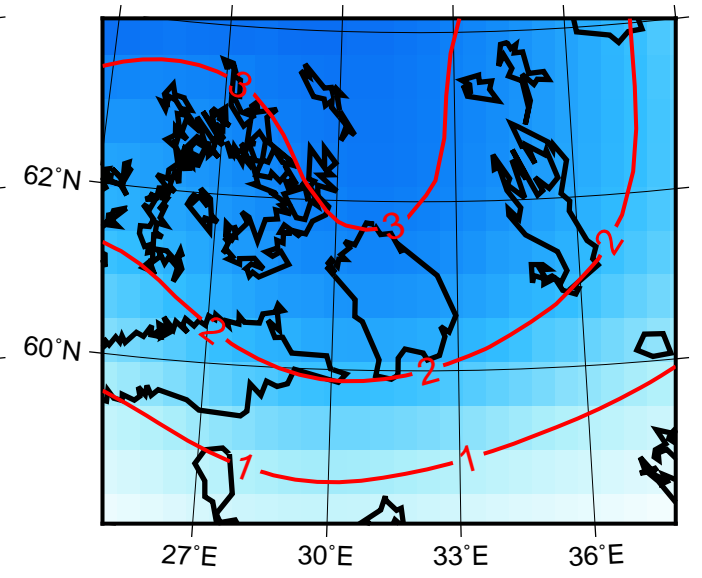

(f)

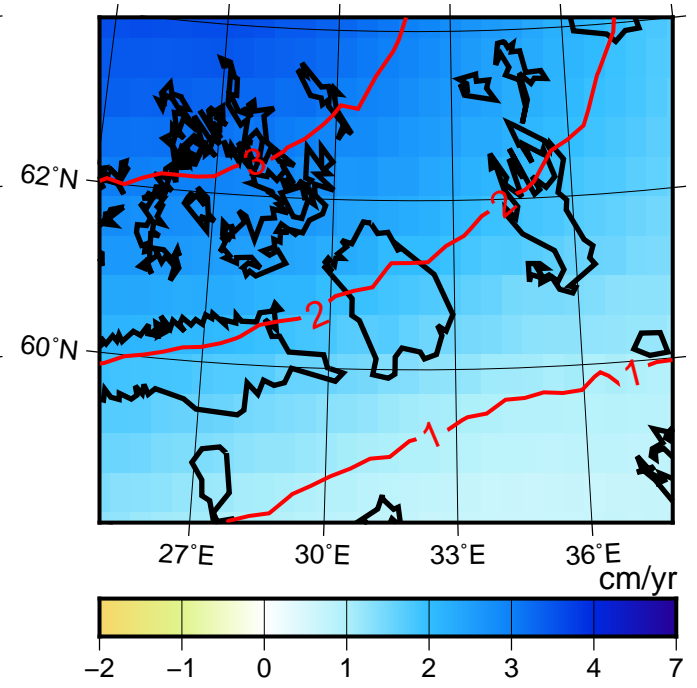

Figure 4: Linear trend in terms of EWH over the Ladoga lake computed in the time interval February 2003 - December 2008 from (a) DMT-2, (b) "DMT-2-DEG-96", (c) CSR-RL05, (d) "CSR-RL05-DDK-5", (e) "CSR-RL05-DDK-8", and (f) GSFC_global_mascons_v01. 
(a)

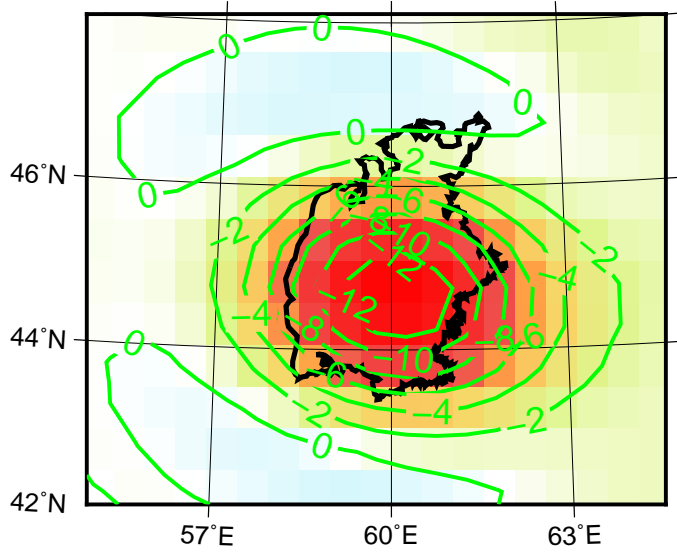

(c)

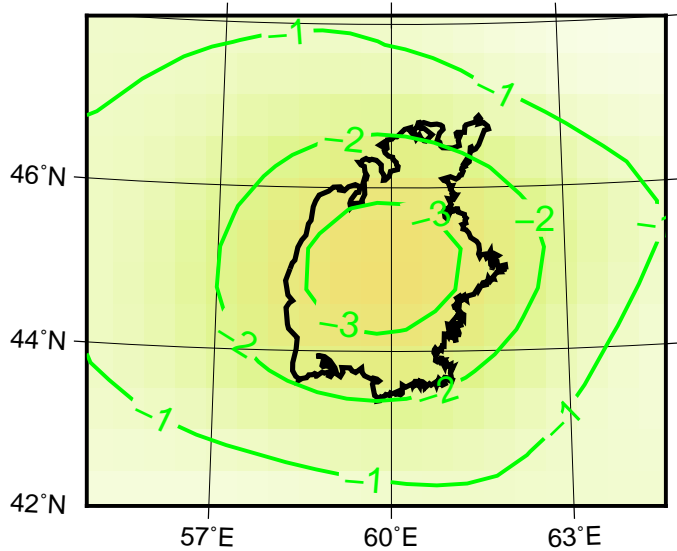

(e)

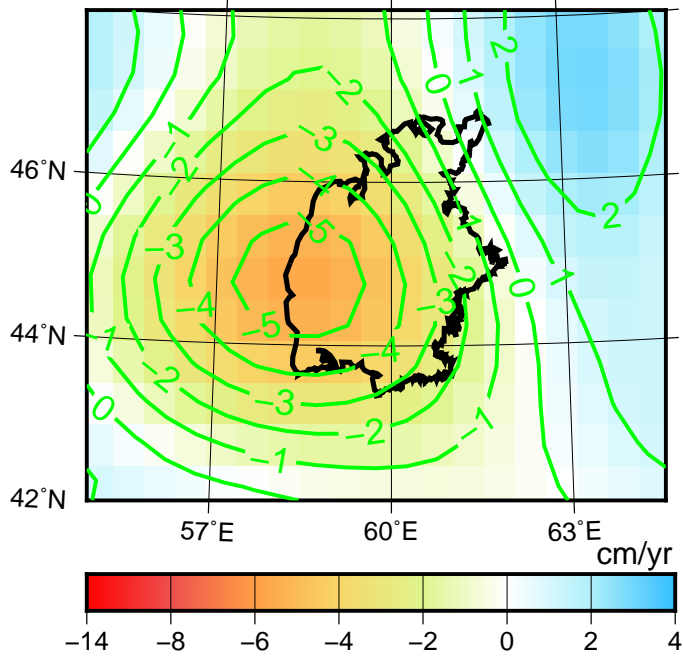

(b)

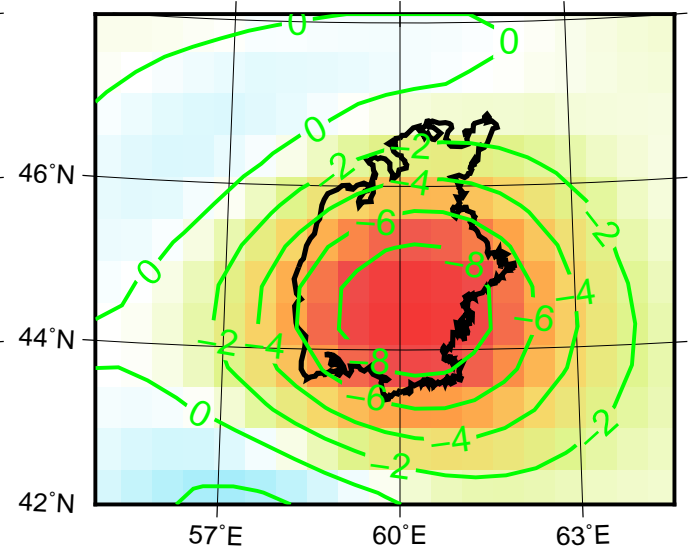

(d)

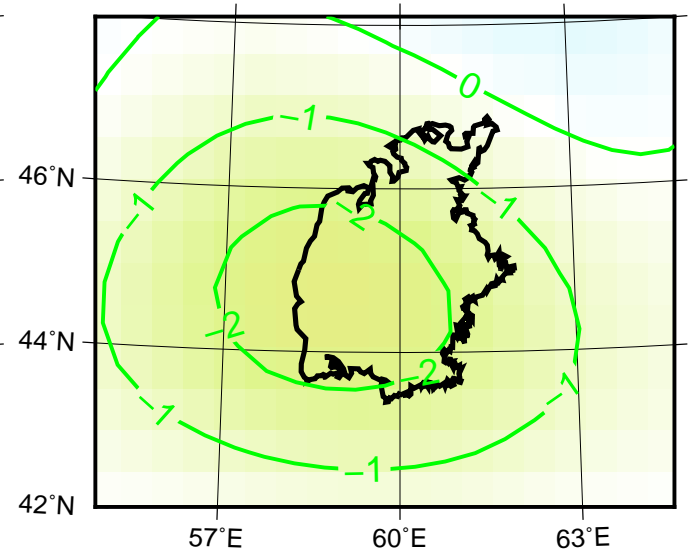

(f)

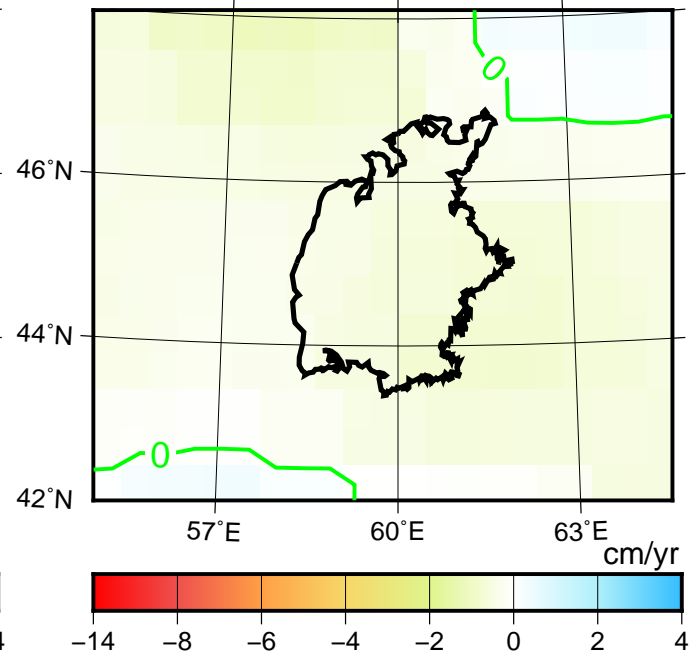

Figure 5: Linear trend in terms of EWH over the Aral sea computed in the time interval February 2003 - December 2008 from (a) DMT-2, (b) "DMT-2-DEG-96", (c) CSR-RL05, (d) "CSR-RL05-DDK-5", (e) "CSR-RL05-DDK-8", and (f) GSFC_global_mascons_v01. 
loss of water mass in the Aral sea. Signal amplitudes are much larger in those cases compared to CSR-RL05, "CSR-RL05-DDK-5", and "CSR-RL05-DDK8". In order to make an independent validation of the results, we consider water levels extracted from TOPEX/Poseidon and Jason-1 radar altimeter data over the period February 2003 - December 2008. From these measurements, we estimate linear trends together with a bias, as well as annual and semi-annual terms, to be consistent with the GRACE-derived estimates. Figure 6 shows the water height variations as a function of time and the computed mean linear trends over the Ladoga lake and Aral sea. A comparison with the GRACE-based estimates reveals that only DMT-2 provides a signal amplitude close to the radar altimeter-based estimates. The amplitude in case of "DMT-2-DEG-96" is reduced by about 20\%. The estimates based on CSR-RL05, "CSR-RL05-DDK-5", and "CSR-RL05-DDK-8" also show mass variations in both areas, but the signal is smeared over a much larger region and dramatically reduced. Correspondingly, linear trends are highly underestimated in those cases for both the Ladoga lake and the Aral sea. This is to be expected for "CSR-RL05-DDK-5" and "CSR-RL05-DDK8 ", because both lakes occupy a relatively small area (about $18000 \mathrm{~km}^{2}$ in 2004). The poor performance observed in case of CSR-RL05 is likely caused by an insufficiently accurate noise covariance matrix, which yields an inadequate Wiener filter. We also notice that the peak mass variations are not centred on the target lakes in case of CSR-RL05, "CSR-RL05-DDK-5", and "CSR-RL05-DDK-8" (an exception is CSR-RL05 for the Aral sea) unlike DMT-2 and "DMT-2-DEG96" (Figs. 4a and 5a). We additionally show in Fig. 7 the Aral sea region observed by the Landsat in summer months in 2003 
(a)

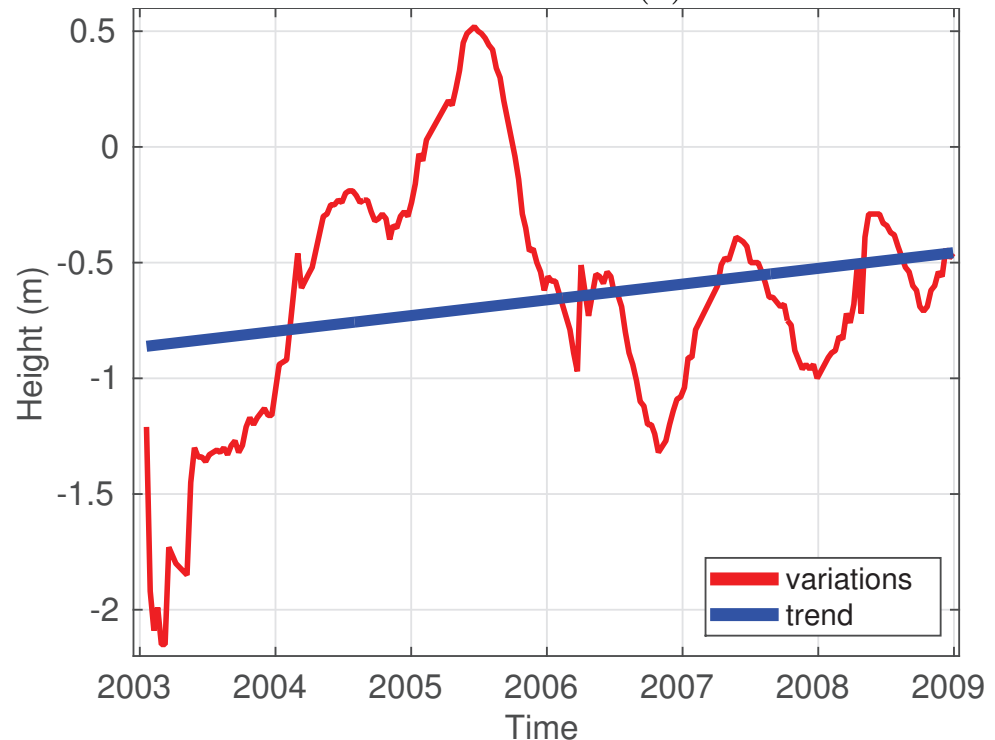

(b)

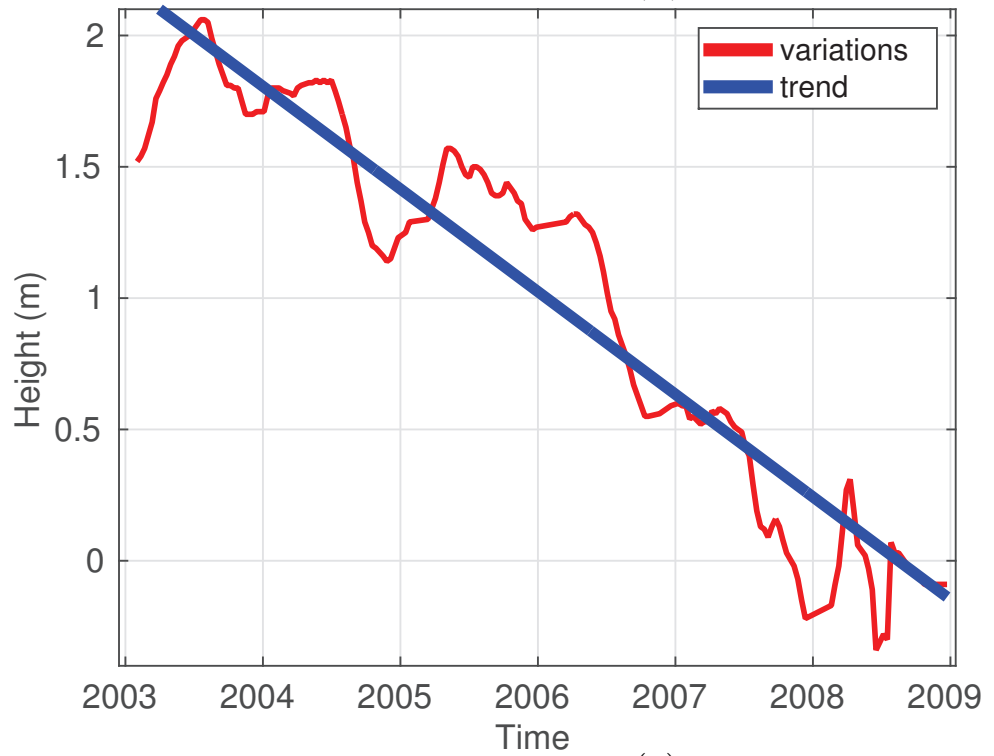

(c)

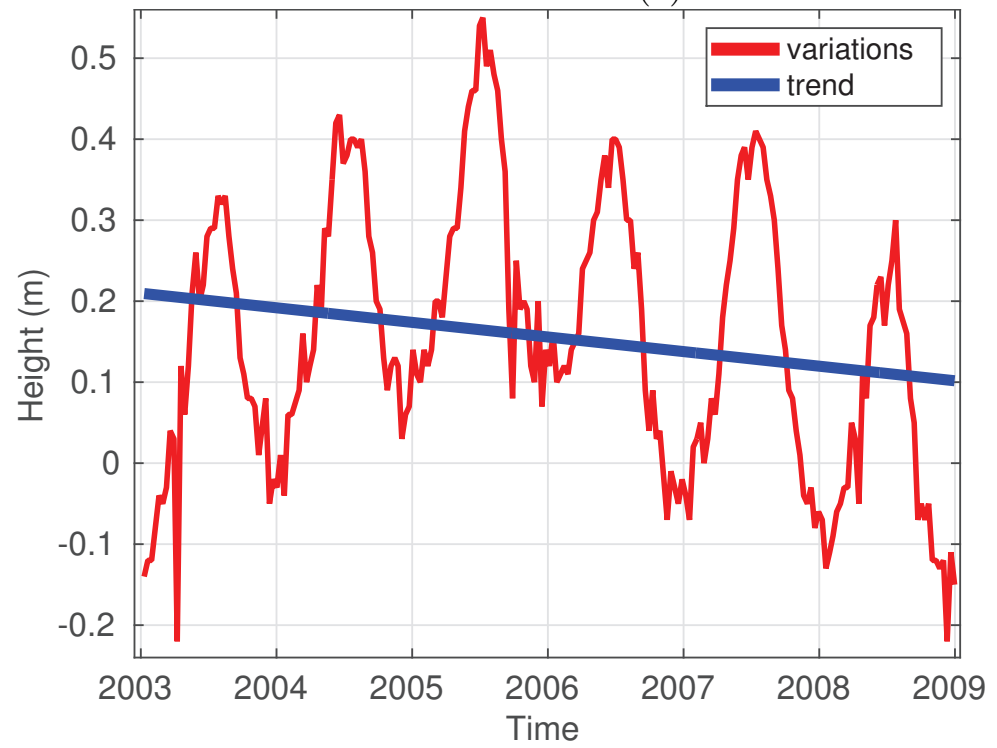

Figure 6: Water height variations and mpen linear trend over (a) Ladoga lake, (b) Aral sea, and (c) Caspian sea in the time interval February 2003 - December 2008 from TOPEX/Poseidon and Jason-1 radar altimeter data. The mean linear trends are $6.92 \mathrm{~cm} / \mathrm{yr},-38.89 \mathrm{~cm} / \mathrm{yr}$, and $-1.64 \mathrm{~cm} / \mathrm{yr}$ for the Ladoga lake, Aral sea, and Caspian sea, respectively. 
- 2008. This time interval corresponds to that for which the linear trend is computed. Summer months are chosen because they offered a clear sky. The figure reveals the presence of a massive water loss. This loss is primarily pronounced in the main water body, i.e., the one centred in the exhibited Landsat pictures. The radar altimeter data exploited in Fig. $6 \mathrm{~b}$ are collected just over this water body, too.

Finally, a comparison between "CSR-RL05-DDK-5" and "CSR-RL05DDK-8" (Fig. 4d versus Fig. 4e and Fig. 5d versus Fig. 5e) clearly reveals an improved spatial resolution when choosing a smaller DDK filter. At the same time, stripes are barely present in case of "CSR-RL05-DDK-8" estimates. Nevertheless, even a small DDK filter could not lead to a spatial resolution achievable with the Wiener filter.

\subsubsection{Ice sheets}

We compare the five spherical harmonic estimates of the linear trend over the Greenland and Antarctica. The linear trend estimates in EWH in the time interval February 2003 - December 2008 are shown over Greenland and Antarctica in Figs. 8 and 9, respectively. The linear trends in physical height changes acquired from ICESat laser altimeter data in the same time interval are provided in Figs. 8f and 9f. These ICESat-based trends are computed using the overlapping footprint approach described in (Felikson et al., 2016) and (Gunter et al., 2014) for Greenland and Antarctica, respectively. In both cases, they have a spatial resolution of about $20 \mathrm{~km}$. We smooth them with a $75 \mathrm{~km}$ (half-width) Gaussian filter (Jekeli, 1981) to facilitate a comparison of them with the GRACE-based estimates (Figs. 8g and 9g). 
(a)

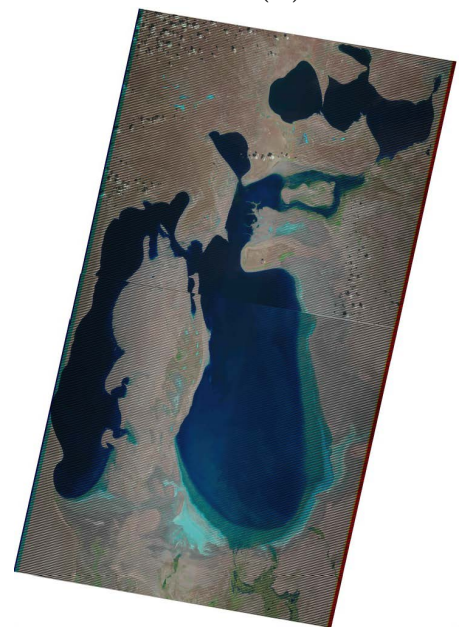

(d)

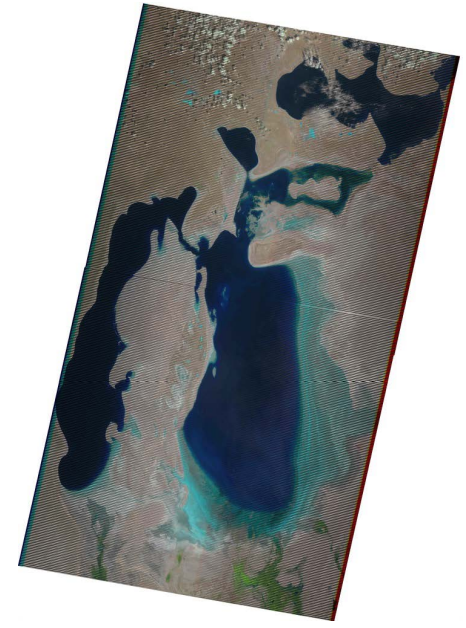

(b)

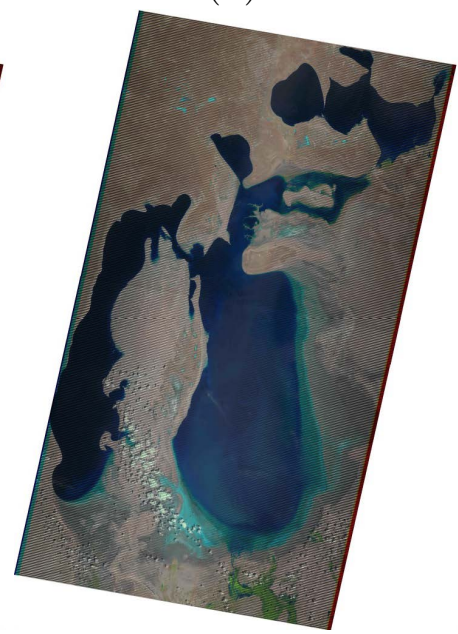

(e)

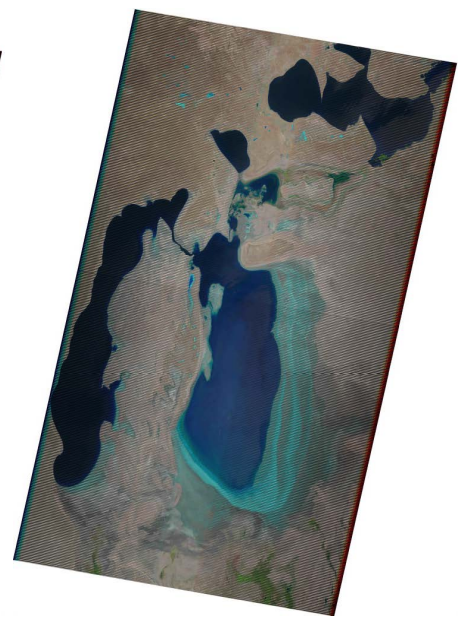

(c)

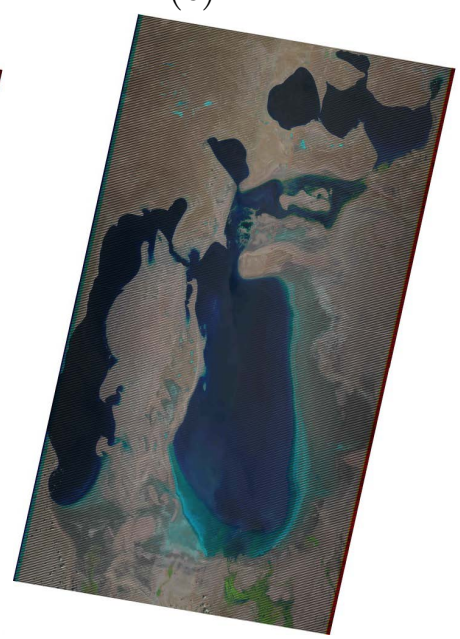

(f)

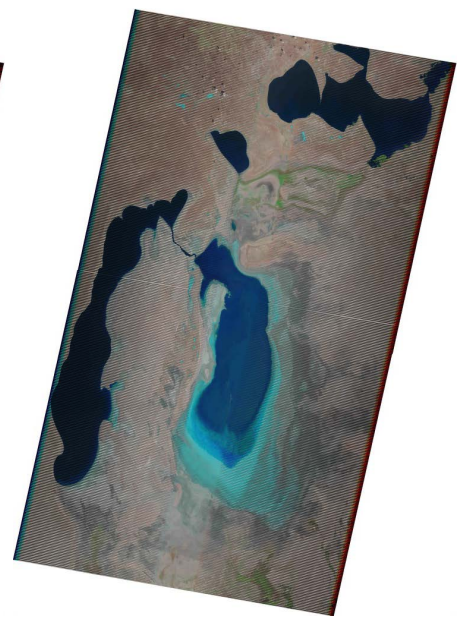

Figure 7: Aral sea region observed by Landsat in 2003 (a) - 2008 (f) in summer months. 

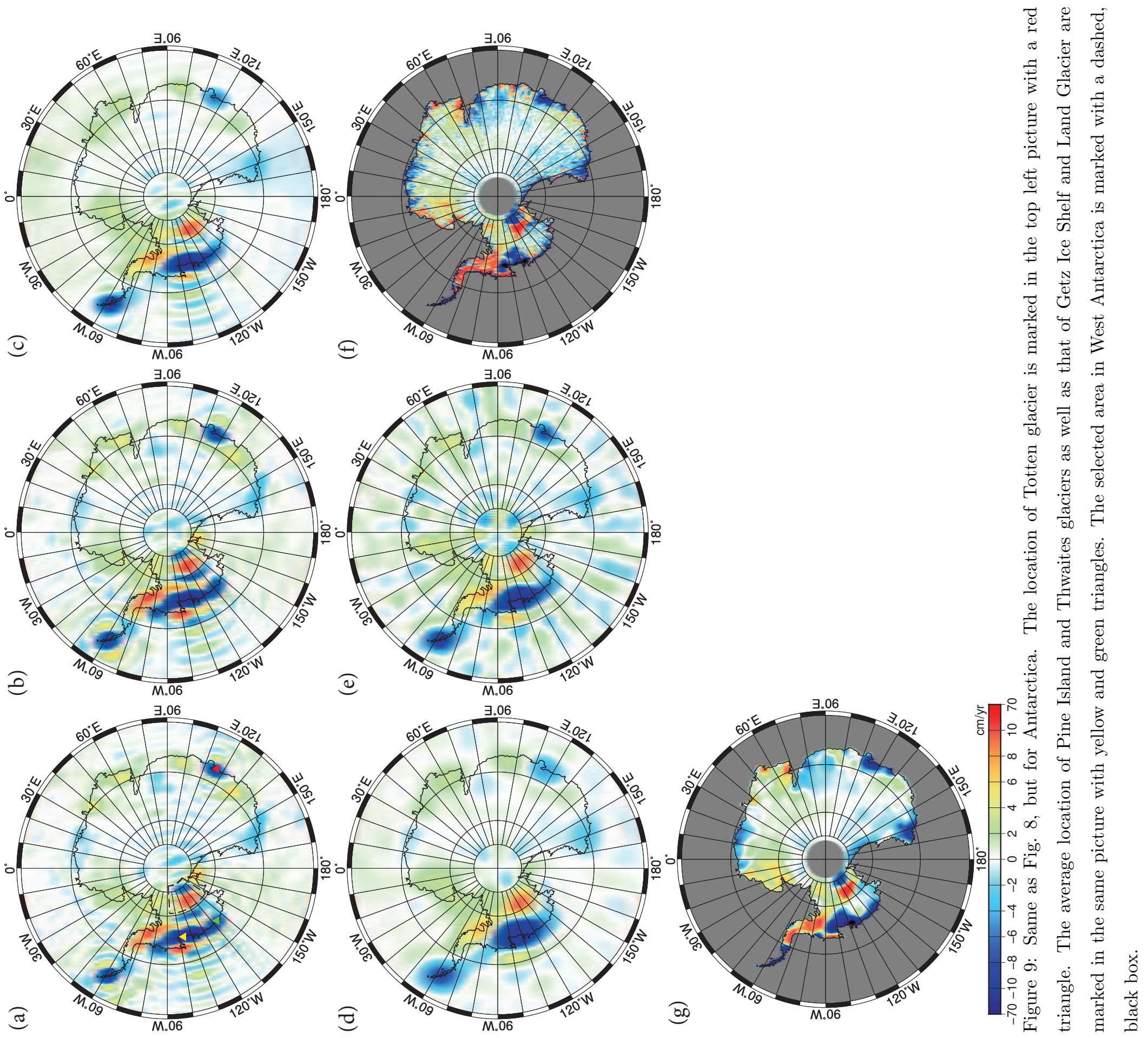
One can see from Figs. 8 and 9 that DMT-2 and its clone computed to degree 96 have the highest spatial resolution allowing for a clear distinction of signals related to individual glaciers. For instance, signals associated with the Jakobshavn and Kangerdlugssuaq glaciers, as well as those related to the combination of Helheim, Ikertivaq, and Koge Bugt glaciers can be clearly seen in Greenland. We also want to point to the good agreement of trend patters over Antarctica from DMT-2 and "DMT-2-DEG-96" with results based on the ICESat data. Examples are signals associated with (i) Totten glacier in East Antarctica, (ii) the combined signal of Pine Island and Thwaites glaciers, and (iii) the combined signal of Getz Ice shelf and Land glacier in West Antarctica. Another notable example is the area near the pole in West Antarctica that is marked by a dashed, black box in Fig. 9a. We zoom in on this region in Fig. 10. DMT-2, "DMT-2-DEG-96", and ICESat data consistently reveal a positive and a negative anomaly there located close to each other. The positive anomaly there is most likely associated with an accumulation of ice, which is in accordance with some earlier findings (e.g., Joughin and Tulaczyk, 2002). Though the CSR-RL05 Wiener filter estimate and its DDK filter variants reveal a similar pattern, the signal amplitude retrieved is somewhat reduced.

At the same time we admit that linear trends from DMT-2 and "DMT-2DEG-96" suffer from some high-frequency errors. They show up in the form of ringing artifacts in the vicinity of locations with strong mass variations. For instance, in Greenland, they are as large as about 12\% of the signal. We consider them as noise given the fact that they are present not only over the ice sheets, but also over the oceans, where mass variations are expected to be 
(a)

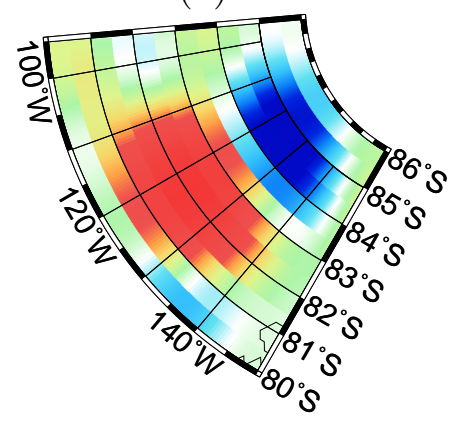

(d)

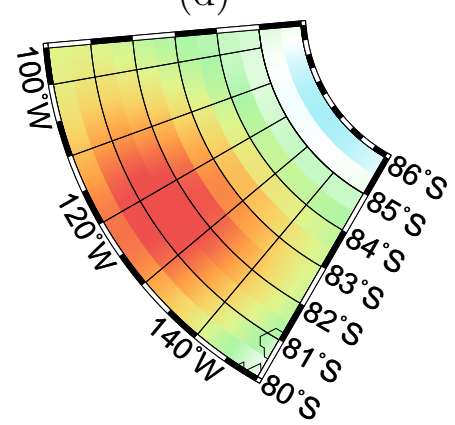

(g)

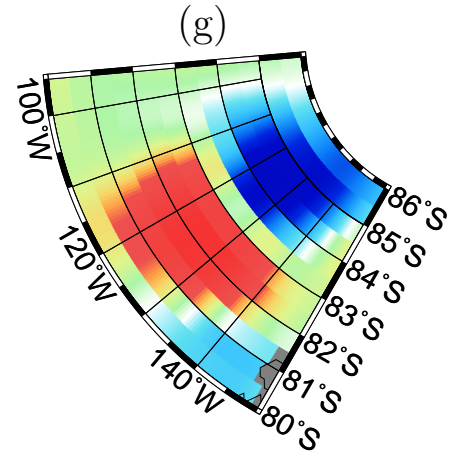

(b)

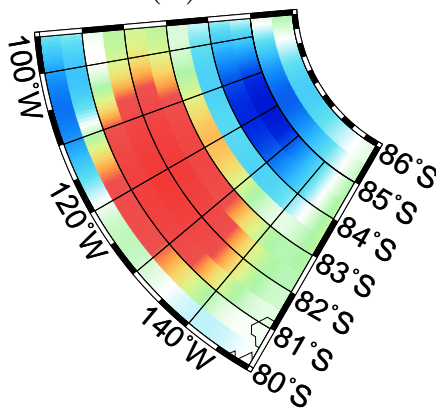

(e)

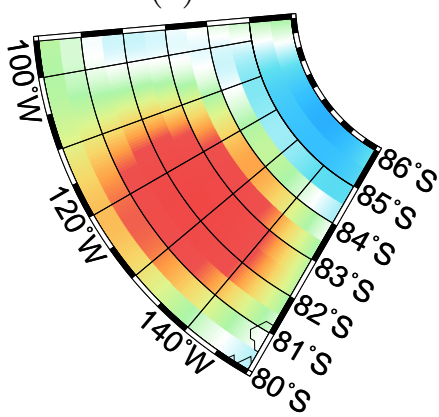

(c)

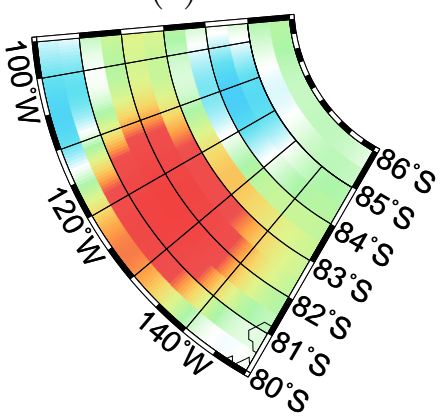

(f)

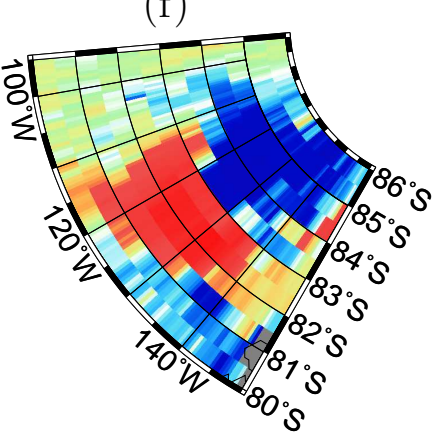

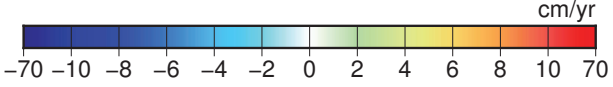

Figure 10: Linear trends over the selected area in West Antarctica, marked with a dashed black box in Fig. 9a. They are computed in the time interval February 2003 - December 2008 from (a) DMT-2, (b) "DMT-2-DEG-96", (c) CSR-RL05, (d) "CSR-RL05-DDK-5", and (e) "CSR-RL05-DDK-8" as well as ICESat data (f) without and (g) with a $75 \mathrm{~km}$ (half-width) Gaussian smoothing. The GRACE-based estimates are in EWH, whereas those based on ICESat are in physical heights. 
minor, if not zero. The likely origin of this phenomenon is an abrupt signal truncation in the frequency domain at the maximum degree (degree 120 and 96 , respectively). The best way to solve this problem is still a topic of active research.

The DDK-filtered linear trend estimates do not offer the spatial resolution achieved in cases of DMT-2 or its clone to degree 96. "CSR-RL05-DDK-8" as compared to "CSR-RL05-DDK-5" reveals a higher spatial resolution in both Greenland and Antarctica. Results related to "CSR-RL05-DDK-8" in Antarctica are somewhat polluted with stripes. In Greenland, however, no sign of stripes is present. This means that a further improvement of spatial resolution could be achieved there when using a smaller DDK filter than the DDK-8 one.

Furthermore, we validate the GRACE models over the Antarctica quantitatively by comparing the results to those derived from laser altimetry (Gunter et al., 2009). To that end, we transform the ICESat-based linear trend estimate from physical heights into EWH in line with the methodology described by Gunter et al. (2014). This approach takes into account surface mass changes from the regional atmospheric climate model RACMO2 (Lenaerts et al., 2012) and the accompanying firn densification model (Ligtenberg et al., 2011) as well as the Glacial Isostatic Adjustment model of Whitehouse et al. (2012). Figure 11 exhibits RMS reductions of the ICESatbased linear trend EWH by the GRACE-based ones in percentages, i.e.,

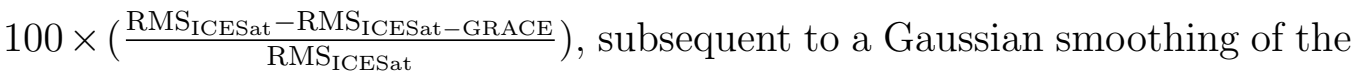
ICESat-based results at different widths. For computing the RMS reduction in percent, the entire ice sheet is seen as a time series. This comparison 


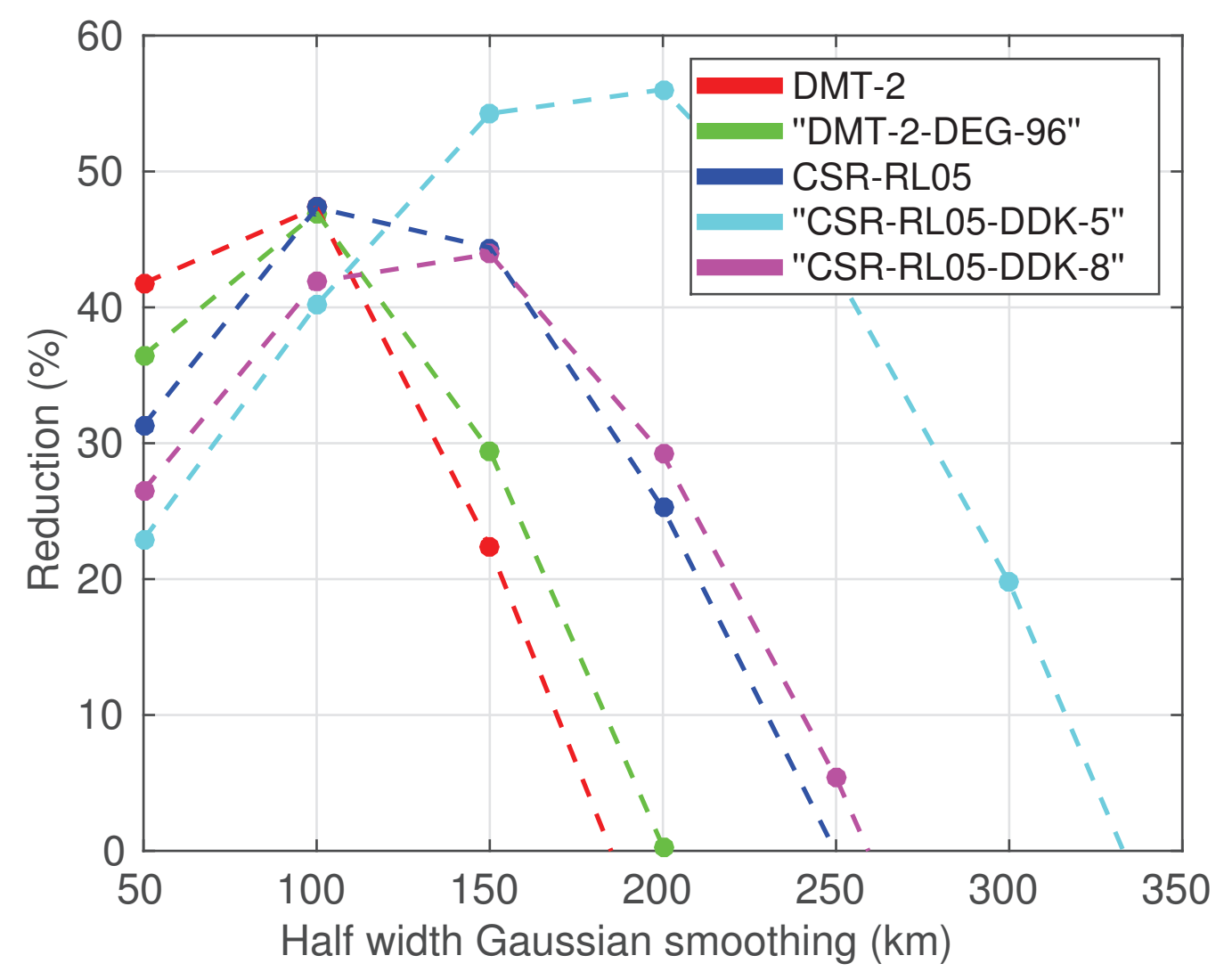

Figure 11: The RMS signal reductions (in percentages) of the ICESat-based linear trend EWH by the GRACE-based ones, i.e., $100 \times\left(\frac{\text { RMS ICESat }_{\text {I }}-\text { RMS ICESat-GRACE }_{\text {ICESat }}}{\text { RMS }_{\text {ICES }}}\right)$, subsequent to the Gaussian smoothing of the ICESat-based results at different widths over Antarctica.

considers both the spatial pattern as well as the magnitude of the signal. The Gaussian smoothing of the ICESat-based results is performed at different widths and compared to the GRACE-derived trend to approximately determine the spatial resolution of the GRACE. The peaks in Fig. 11 are interpreted as the spatial resolution of the respective GRACE solution in terms of the Gaussian smoothing filter. Compared to CSR-RL05, the computed signal reductions are slightly larger for DMT-2 and "DMT-2-DEG-96" 
at spatial scales smaller than about $100 \mathrm{~km}$ (half-width). The opposite is observed at larger spatial scales. We interpret this observation as an evidence that the spatial resolution of the DMT-2 model and its clone is higher. To understand this behaviour, we emphasize that only the ICESat-based results are subject to the Gaussian smoothing. Hence, the spatial resolution of those results reduces as the spatial scale increases. Consequently, for GRACE estimates with higher spatial resolution, the peak in their signal reductions of the ICESat-based EWH occurs at smaller smoothing radii.

Furthermore, it is worth noting that the signal reductions in the case of the CSR-RL05 Wiener filter estimate are much higher than in case of the DDK-filtered ones at spatial scales smaller than 100 - $150 \mathrm{~km}$ (half-width). We interpret this as a consequence of a higher spatial resolution of the Wiener filter compared to the DDK filters. This is also supported by the maps shown in Figs. 8, 9, and 10.

On the other hand, as it can be seen from Fig. 9, the higher the spatial resolution of a GRACE solution, the higher its noise content. The ringing artifacts can be clearly seen for the Wiener filter estimates in Fig. 9 and they are also reflected in the lower values of RMS reduction for these solutions compared to the DDK-filtered estimates at relatively large spatial scales.

Finally, it is important to note that DMT-2 as compared to its clone computed to degree 96 reveals a slightly better agreement with the ICESat-based estimates at spatial scales smaller than 100-150 km (half-width). However, it should be noted that this must be almost entirely attributed to a higher maximum degree considered at the filtering stage and not to information content of KBR data (Farahani, 2013). 


\subsubsection{A preliminary comparison with a mascon parametrization}

Figure 12 shows the linear trends estimated based on the DMT-2 spherical harmonic (to degree 120) and GSFC_global_mascons_v01 mascon models in the time interval February 2003 - December 2008 in terms of EWH at the global scale. The colore scale is intentionally saturated in order to reveal model differences more clearly. Both models demonstrate a high spatial resolution. This is, in particular, notable in areas where substantial mass variations occur, e.g., Antarctica, Greenland, Gulf of Alaska, Iceland, Canadian Arctic archipelago, Novaya Zemlya archipelago, and Svalbard (Spitsbergen) archipelago. DMT-2 and GSFC_global_mascons_v01 both demonstrate a high concentration of the signal along the coast in these areas. This is typically expected in the case of mascon models due to a priori information imposed, for instance, by defining the mascon geometry consistently with coast lines. We find this, however, remarkable in the case of DMT-2 in view of the fact that no such a priori information is imposed.

DMT-2 as compared to GSFC_global_mascons_v01 suffers from somewhat larger inaccuracies in the so-called "quite areas", i.e., areas void of substantial temporal gravity field variations (e.g., oceans and deserts), which is partly explained by the presence of the previously noted ringing artifacts. Finding the best way to suppress those inaccuracies will be the subject of a future research. This, for instance, could be done by additional filtering of spherical harmonic coefficients by preventing the signal variances (i.e., diagonal elements in matrix D) in "quite areas" from exceeding a predefined threshold. Finally, one can identify numerous differences between the DMT-2 and GSFC_global_mascons_v01 models at small spatial scales. Examples are Lake 
(a)

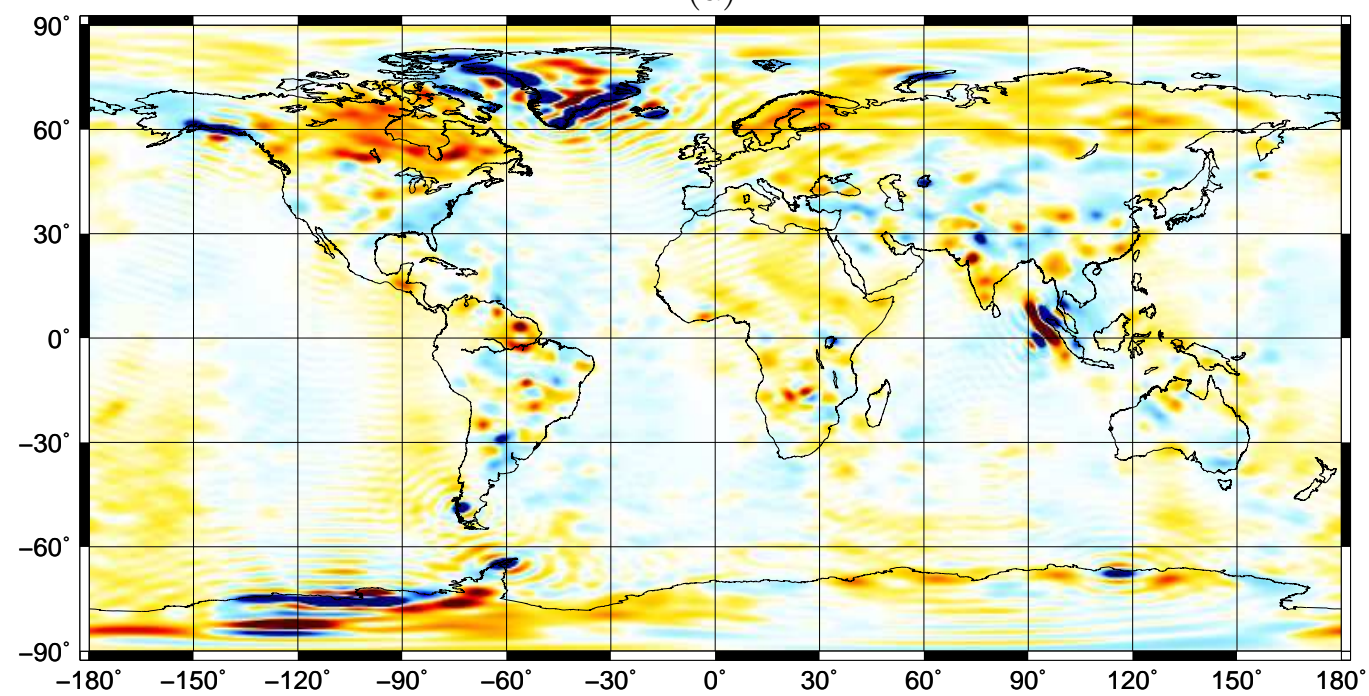

(b)
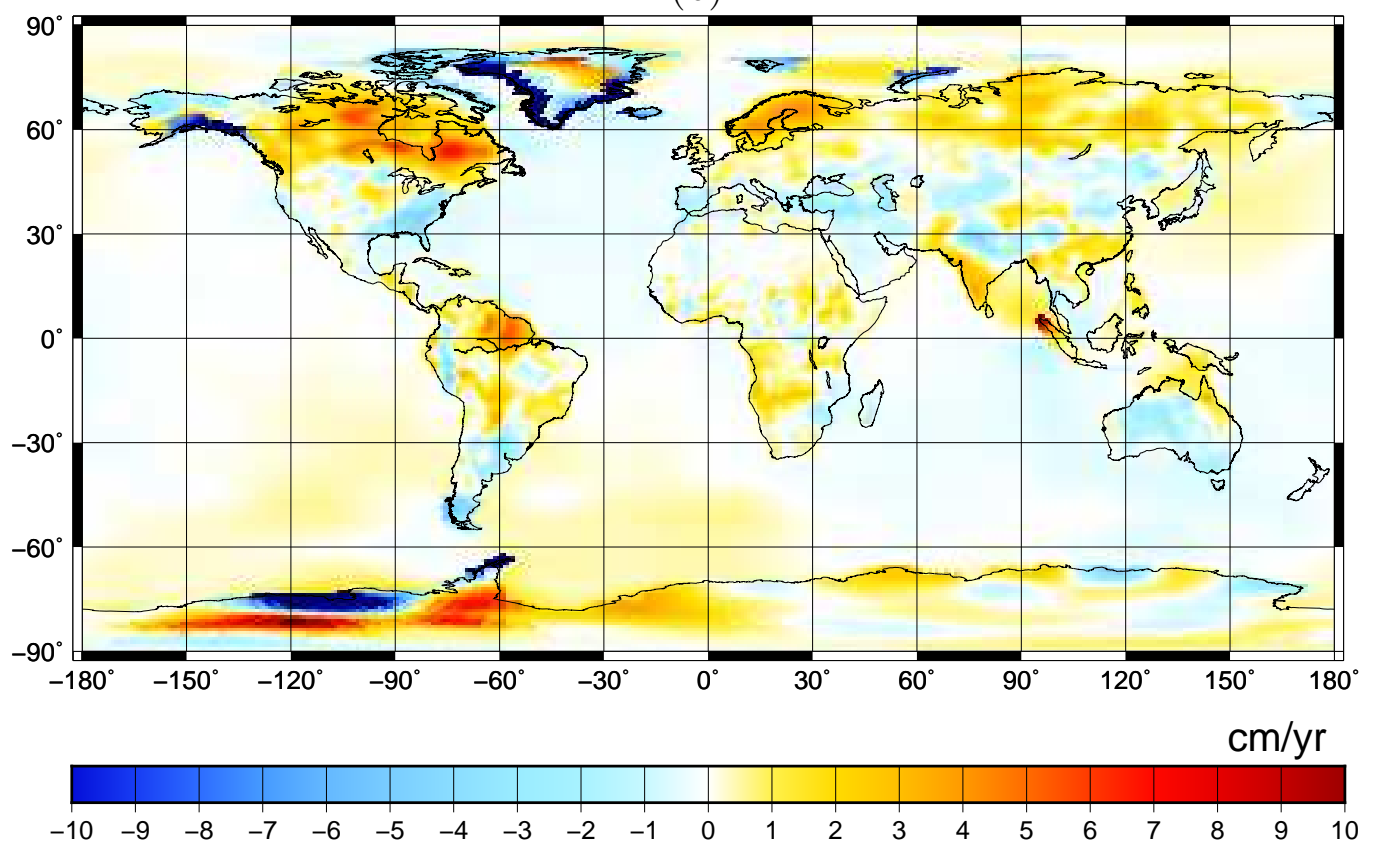

Figure 12: The linear trend computed in the time interval February 2003 - December 2008 in the cases of (a) DMT-2 and (b) GSFC_global_mascons_v01. The maps are in terms of EWH. Their RMS values are (a) $3.19 \mathrm{~cm} / \mathrm{yr}$ and (b) $1.58 \mathrm{~cm} / \mathrm{yr}$. The Color scale is intentionally saturated. 
Victoria, Ladoga lake, Aral sea, Caspian sea, Amazon river basin, and Patagonia. A comprehensive analysis of such differences demands a separate research, which we postpone to a later stage. Here, we limit ourselves to only three water bodies: Aral sea, Ladoga lake, and Caspian sea. In Ladoga lake and Aral sea, GSFC_global_mascons_v01, unlike DMT-2, fails to capture respective water gain and water loss signals (see Fig. 4a versus Fig. 4f and Fig. 5a versus Fig. 5f as well as Fig. 6a and Fig. 6b). On the contrary, GSFC_global_mascons_v01 reveals the water loss in the Caspian sea. DMT2 fails in that respect and, by the way, so do all other spherical harmonic models considered in our manuscript (cf. Fig. 3c - Fig. 3e). The reason for this is yet to be investigated. It is worth noting that the loss of water in the Caspian sea in the time interval under consideration is captured by radar altimetry data, too (cf. Fig. 6c).

\section{Conclusions}

We computed new estimates of the long-term linear trend in mass redistribution based on the DMT-2 model, which comprises monthly gravity field solutions and corresponding full noise covariance matrices complete to spherical harmonic degree 120. A novel feature of the DMT-2 model is the accurate computation and incorporation of stochastic properties of coloured noise when processing KBR data, which also accounts for gradual variations of the noise characteristics in time. This ensures a statistically optimal inversion of KBR data, and more importantly, an accurate computation of noise covariance matrices of monthly solutions. These matrices play a key role in the design of Wiener-type filters, including that proposed by Siemes et al. 
(2013) for estimating the linear trend. For comparison, we produced estimates of the linear trend from CSR-RL05 monthly solutions and their noise covariance matrices using the same methodology to build the linear trend Wiener filter. The linear trend estimate based on DMT-2 demonstrates a higher spatial resolution, even if we lower the maximum degree in the DMT2 model to degree 96 to be consistent with the CSR-RL05 model. It allows for a clear detection of mass variation signals in relatively small water bodies and individual outlet glaciers of the ice sheets. Moreover, it shows a much better fit to actual water level and surface elevation variations extracted from radar and laser altimeter data. We attribute the higher spatial resolution of the DMT-2 linear trend estimates compared to that estimated from CSR-RL05 to an accurate computation of monthly noise covariance matrices, which was possible due to a proper handling of coloured noise in KBR data. However, there is still space for further improvements. The linear trend estimates based on DMT-2 or its clone computed to degree 96 suffer from some high-frequency inaccuracies. Those inaccuracies manifest themselves in the form of ringing artifacts in the vicinity of locations with strong mass variations. The best way to deal with this problem is still under investigation. The estimates of the linear trend obtained from DMT-2 are publicly available for download., ${ }^{1,2}$ The linear trend models analysed and presented in this manuscript are related to a six-year time interval (February 2003 December 2008). Similar models for longer time intervals are to be produced and released subsequently.

\footnotetext{
${ }^{1}$ www.citg.tudelft.nl

${ }^{2}$ www.researchgate.net/profile/Hassan_H_Farahani
} 
Furthermore, we produced additional variants of the linear trend with a commonly-used approach: from CSR-RL05 monthly solutions subject to the DDK-5 and DDK-8 de-correlating non-isotropic filters. As compared to the Wiener filters, these variants showed a reduced spatial resolution and signal power. In a comparison with the altimetry-based results over Antarctica, the linear trends obtained in this way showed peak spatial resolutions about twice (in case of DDK-5 filtering) and 1.5 times (in case of DDK-8 filtering) as coarse as those after the Wiener filtering. Thus, the DDK-8 filtering showed a notably higher spatial resolution than the DDK-5 filtering. Near the equator, nevertheless, the DDK-8-filtered results showed strong stripes. This implies that a smaller DDK filter cannot be successfully applied uniformly over the entire globe. We conclude that when estimating the linear trend based on DDK-filtered time series of solutions, one needs to choose different DDK filters for different geographical areas.

A comparison of DMT-2 with GSFC_global_mascons_v01, a recent global mascon model, suggests that both models demonstrate a high spatial resolution in areas known for substantial temporal gravity field changes (e.g., Antarctica, Greenland, Gulf of Alaska, Iceland, Canadian Arctic archipelago, Novaya Zemlya archipelago, and Svalbard archipelago). DMT-2 compared to GSFC_global_mascons_v01 showed somewhat larger inaccuracies in areas known for minor mass variations (e.g., ocean and deserts). The absence of such inaccuracies in GSFC_global_mascons_v01 is explained by a priori information typically imposed in such areas, for instance, by defining the mascon geometry consistently with coast lines (e.g., Watkins et al., 2015). Such a priori information was never used when computing DMT-2. To the knowl- 
edge of authors, they are absent in all spherical harmonic models produced so far. An incorporation of such a priori information in the production of future spherical harmonic models could be the subject of future research endeavours. This could be incorporated at the a posteriori stage, i.e., when filtering spherical harmonic coefficients. More specifically, this could be done by predefining and enforcing relatively small signal variances in areas with minor mass variations when building and applying a Wiener-type filter. Finally, the comparison revealed numerous differences between DMT-2 and GSFC_global_mascons_v01 at small spacial scales. A verification of a few of those features, namely, in Ladoga lake, Aral sea, and Caspian sea, led to mixed conclusions in favour of either model in each instance. An in-depth comparison of other small scale differences is postponed to further publications. It is worth noting that spherical harmonic and mascon models use vastly different parametrizations. That is, they belong to two vastly different classes of time-varying gravity field models. Hence, an in-depth comparison of them deserves a separate research in any way.

\section{Acknowledgments}

The research was financially supported by the Nederlandse organisatie voor Wetenschappelijk Onderzoek (Netherlands Organization for Scientific Research, NWO). High-performance computing facilities were provided by the Stichting Nationale Computerfaciliteiten (National Computing Facilities Foundation, NCF). GRACE level-1B data were provided by the Jet Propulsion Laboratory (JPL). The CSR-RL05 unconstrained monthly solutions as well as those constrained by the DDK- 5 and DDK- 8 filters were provided by 
the International Centre for Global Earth Models (ICGEM). The CSR-RL05 monthly noise covariance matrices were provided by the Center for Space Research (CSR) at the University of Texas at Austin. Landsat pictures as well as TOPEX/Poseidon and Jason-1 radar altimeter data were made available by the US Geological Survey (USGS) and the US Department of Agriculture (USDA), respectively. GSFC_global_mascons_v01 was provided by Goddard Space Flight Center (GSFC). These supports are gratefully acknowledged. We are thankful to Natthachet Tangdamrongsub for an assistance in compiling the Landsat pictures. We thank the editor, Volker Klemann, and two anonymous reviewers for their constructive remarks and corrections, which helped us to improve the quality of the manuscript.

\section{Appendix A. Residual data}

DMT-2 like its predecessor DMT-1 used a variant of the acceleration approach. So-called "range combinations" were obtained from bias-corrected inter-satellite ranges at three successive epochs with a three-point double differentiation scheme (Liu, 2008; Liu et al., 2010)

$$
\begin{aligned}
\bar{a}(t)=\frac{\mathbf{e}(t-\Delta t) \cdot \mathbf{e}(t) \rho(t-\Delta t)-2 \rho(t)}{(\Delta t)^{2}} & \\
+ & \frac{\mathbf{e}(t) \cdot \mathbf{e}(t+\Delta t) \rho(t+\Delta t)}{(\Delta t)^{2}},
\end{aligned}
$$

with $\Delta t$ the sampling rate, $\rho(t)$ the bias-corrected inter-satellite ranges, and $\mathbf{e}(t)$ the line-of-sight unit vectors pointing from the trailing to the leading satellite, and $t$ the measurement epoch. It is, in essence, similar to a scheme developed earlier by Ditmar and van Eck van der Sluijs (2004) and Ditmar 
et al. (2006) to determine the Earth's gravity field from kinematic orbits of low Earth orbiters.

To reduce KBR data into residual range combinations, the following background force models were used:

(i) Static gravity field with DGM-1S (Farahani et al., 2013a,b).

(ii) Third-body perturbations from the JPL DE405/LE405 lunar and planetary ephemerides (Standish, 1998).

(iii) Solid Earth and pole tides in line with the 2003 conventions of the International Earth Rotation and Reference Systems Service (IERS) (McCarthy and Petit, 2004).

(iv) Ocean tides according to EOT11a to spherical harmonic degree 80 (Savcenko et al., 2012).

(v) Non-tidal atmospheric and oceanic variations from the fifth release of the Atmosphere and Ocean De-aliasing level-1b (AOD1B) product to spherical harmonic degree 100 (Dobslaw et al., 2013).

(vi) Ocean pole tide defined by the model of Desai (2002) to spherical harmonic degree 30.

(vii) General relativity corrections in line with the IERS 2003 conventions (McCarthy and Petit, 2004).

(viii) Non-gravitational perturbations from the second release of GRACE accelerometer and attitude data, which are provided as a part of GRACE level-1B data (Case et al., 2004).

Additionally, the background force models were iteratively improved. The production of the monthly solutions involved three iterations, in all of which 
the gravity field retrieval was performed to degree 120. The first two iterations were executed in line with Liu et al. (2010). That is, the unconstrained solutions computed at a given iteration were truncated at degree 13 and included into the list of background force models used in the next iteration. In the third iteration, the solutions of the previous iteration were treated differently. Instead of a truncation, they were processed by applying the Wiener-type filter (Klees et al., 2008b). They were then included into the list of the background force models to obtain the unconstrained solutions at the third (i.e., final) iteration. The GRACE satellites in several time intervals, namely, September - October 2004, November - December 2009, and January - February 2010, followed an orbit with a relatively short repeat period. This leads to relatively high inaccuracies in the unconstrained solutions for these months (e.g., Farahani et al., 2014). These inaccuracies occur in the entire range of degrees, including those below degree 13. Thus, performing the second iteration as described above would not lead to optimal results. Hence, DMT-2 solutions for these months were computed by performing the second iteration in the same manner as the third one, so that noise in unconstrained solutions, however large, was efficiently suppressed in the entire range of degrees.

The background force models entered a dynamic orbit computation in line with Zhao (2004). The orbital arc length was set equal to six hours. The orbit computation included a least-squares estimation of the initial state vector elements and accelerometer's bias parameters per arc as well as of accelerometer's scaling factors per month. This estimation was done by fitting the orbits to input kinematic orbits or reduced-dynamic orbits. For the 
time interval February 2003 - December 2005, reduced-dynamic orbits were exploited as input, which were kindly provided by Kroes et al. (2005). For the rest of the time interval, kinematic orbits were exploited, which were produced in the GNSS Research Center of Wuhan University in line with Zhao (2004).

Observed inter-satellite ranges were obtained from the second release of GRACE level-1B data. These data are biased due to phase ambiguities. The dynamic orbits were used to estimate a bias per continuous data segment by least-squares. In addition, the dynamic orbits were used to compute a priori inter-satellite ranges. Subsequently, residual inter-satellite ranges were obtained by subtracting the a priori inter-satellite ranges from the observed bias-corrected ones. Finally, the residual inter-satellite ranges were used to compute residual range combinations in line with Eq. A.1.

The obtained residual range combinations suffer from a low-frequency noise below $2-3$ cycles per revolution (cpr) (e.g., Liu, 2008), which is mainly caused by dynamic orbit errors (Ditmar et al., 2012). This noise was approximated per orbital revolution with a seven-parameter function used earlier in (e.g., Kim, 2000; Liu et al., 2010):

$$
\begin{aligned}
r(t)=x_{0}+x_{1} t+x_{2} \cos \omega t+x_{3} \sin \omega t & \\
& +x_{4} t \cos \omega t+x_{5} t \sin \omega t+x_{6} t^{2} .
\end{aligned}
$$

Herein, $\omega=\frac{2 \pi}{T}$ is the orbital angular velocity with $T$ being the orbital period. The unknowns $x_{0} \ldots x_{6}$ were estimated from residual data using leastsquares. Thereafter, the estimated model was removed from the residuals. Note that time-varying gravity field signals, which are to be retrieved at a 
later stage, play a role of noise in the context of this least-squares adjustment.

If the presence of this noise is ignored, as it was done when computing DMT1, the estimated function will tend to explain not only the low-frequency noise in the residuals, but also a part of time-varying gravity field signals. Consequently, these signals may be partly removed from the data. In particular, this concerns signals associated with spherical harmonic degrees below 4 (Farahani et al., 2013a). To mitigate this effect, the least-squares adjustment was performed with a spatially-dependent data weighting, whose details are provided in (Farahani et al., 2014). The scheme ensures that residual data collected over areas with minor mass variations (e.g., in the oceanic areas and deserts) get the largest weights in this adjustment.

\section{Appendix B. Computing DMT-2 clone to degree 96}

To compute clones of DMT-2 monthly gravity field solutions to degree 96, we begin with the original DMT-2 unconstrained solutions, which are complete to degree 120, and their noise covariance matrices. We first compute the right-hand side vectors of the systems of linear equations associated with the monthly unconstrained solutions to degree 120

$$
\mathbf{u}_{(k)}^{120}=\left(\mathbf{C}_{\hat{\mathbf{x}}^{(k)}}^{120}\right)^{-1} \hat{\mathbf{x}}_{(k)}^{120}
$$

with $\hat{\mathbf{x}}_{(k)}^{120}$ and $\mathbf{C}_{\hat{\mathbf{x}}^{(k)}}^{120}$ being respectively the unconstrained solution to degree 120 and its noise covariance matrix for month $k$. A truncation of $\mathbf{u}_{(k)}^{120}$ and $\left(\mathbf{C}_{\hat{\mathbf{x}}^{(k)}}^{120}\right)^{-1}=\mathbf{N}_{(k)}^{120}$, i.e., the corresponding normal matrix, at degree 96, which can be done with ease, allows monthly unconstrained solutions to degree 96 to be computed

$$
\hat{\mathbf{x}}_{(k)}^{96}=\mathbf{C}_{\hat{\mathbf{x}}^{(k)}}^{96} \mathbf{u}_{(k)}^{96}
$$


578 with $\mathbf{C}_{\hat{\mathbf{x}}^{(k)}}^{96}=\left(\mathbf{N}_{(k)}^{96}\right)^{-1}$ being the noise covariance matrix of $\hat{\mathbf{x}}_{(k)}^{96}$. Herein, ${ }_{579} \quad \mathbf{N}_{(k)}^{96}$ and $\mathbf{u}_{(k)}^{96}$ respectively symbolize the monthly normal matrices and right580 hand-side vectors truncated at degree 96.

581

\section{References}

Bamber JL, Riva REM, Vermeersen BLA, LeBrocq AM (2009) Reassessment of the potential sea-level rise from a collapse of the West Antarctic ice sheet, Science, 324: 901-903, doi: 10.1126/science.1169335.

Baur O, Sneeuw N (2011) Assessing Greenland ice mass loss by means of point-mass modeling: a viable methodology, J Geod, 85: 607-615, doi: 10.1007/s00190-011-0463-1.

Bettadpur S (2007) CSR Level-2 processing standards document for product release 04, GRACE 327-742, Revision 3.1.

Bettadpur S (2012) CSR level-2 processing standards document for level-2 product release 05, GRACE 327-742.

Bruinsma SL, Lemoine J-M, Biancale R, Valès N (2010) CNES/GRGS 10day gravity field models (release 2) and their evaluation, Adv Space Res, 45: 587-601, doi: 10.1016/j.asr.2009.10.012.

Case K, Kruizinga GLH, Wu S-C (2004) GRACE Level-1B data product user handbook, Jet Propulsion Laboratory, California Institute of Technology, JPL D-22027. 
Chen Q, Shen Y, Zhang X, Hsu H, Chen W, Ju X, Lou L (2015) Monthly gravity field models derived from GRACE level 1B data using a modified shortarc approach, J Geophys Res, 120, 1804-1819, doi: 10.1002/2014JB011470.

Dahle C, Flechtner F, Gruber C, König D, König R, Michalak G, Neumayer K-H (2012) GFZ GRACE level-2 processing standards document for level-2 product release 05, Technical Report STR12/02, doi: 10.2312/GFZ.b10312020.

Desai SD (2002) Observing the pole tide with satellite altimetry, J Geophys Res, 107(C11), 3186, doi: 10.1029/2001JC001224.

Ditmar P, van Eck van der Sluijs AA (2004) A technique for modeling the Earth's gravity field on the basis of satellite accelerations, J Geod, 78: 12-33, doi: 10.1007/s00190-003-0362-1.

Ditmar P, Kuznetsov V, van Eck van der Sluijs AA, Schrama E, Klees R (2006) DEOS_CHAMP-01C-70: a model of the Earth's gravity field computed from accelerations of the CHAMP satellite, J Geod, 79: 586-601, doi: 10.1007/s00190-005-0008-6.

Ditmar P, Teixeira da Encarnação J, Farahani HH (2012) Understanding data noise in gravity field recovery on the basis of inter-satellite ranging measurements acquired by the satellite gravimetry mission GRACE, J Geod, 86: 441-465, doi: 10.1007/s00190-011-0531-6.

Dobslaw H, Flechtner F, Bergmann-Wolf I, Dahle C, Dill R, Esselborn S, Sasgen I, Thomas M (2013) Simulating high-frequency atmosphere-ocean 
mass variability for de-aliasing of satellite gravity observations: AOD1B RL05, J Geophys Res, 118: 3704-3711, doi: 10.1002/jgrc.20271.

Farahani HH (2013) Modelling the Earth's static and time-varying gravity field using a combination of GRACE and GOCE data, PhD Thesis, Delft University of Technology, Delft, The Netherlands, doi: 10.13140/RG.2.1.3104.3286.

Farahani HH, Ditmar P, Klees R, Liu X, Zhao Q, Guo J (2013a) The static gravity field model DGM-1S from GRACE and GOCE data: computation, validation and an analysis of GOCE mission's added value, J Geod, 87: 843-867, doi: 10.1007/s00190-013-0650-3.

Farahani HH, Ditmar P, Klees R, Teixeira da Encarnação J, Liu X, Zhao Q, Guo J (2013b) Validation of static gravity field models using GRACE Kband ranging and GOCE gradiometry data, Geophys J Int, 194: 751-771, doi: $10.1093 /$ gji/ggt149.

Farahani HH, Ditmar P, Klees R (2014) Assessment of the added value of data from the GOCE satellite mission to time-varying gravity field modeling, J Geod, 88: 157-178, doi: 10.1007/s00190-013-0674-8.

Felikson D, Urban TJ, Pie N, Gunter B, Harpold R, Schutz BE (2016) Comparison of repeat track, crossover, and overlapping footprint elevation change methods from satellite altimetry: ICESat-1 elevation changes of Greenland and Antarctica (in review).

Flechtner F (2007) GFZ Level-2 processing standards document for product release 04, GRACE 327-743, GR-GFZ-STD-001. 
Gunter BC, Wittwer T, Stolk W, Klees R, Ditmar P (2009) Comparison of regional and global GRACE gravity field models at high latitudes, in Kenyon S, Pacino MC, Marti U (eds.), Geodesy for Planet Earth, International Association of Geodesy Symposia 136, pp. 171-177, doi: 10.1007/978-3642-20338-1_21.

Gunter BC, Didova O, Riva REM, Ligtenberg SRM, Lenaerts JTM, King MA, van den Broeke MR, Urban T (2014) Empirical estimation of presentday Antarctic glacial isostatic adjustment and ice mass change, The Cryosphere, 8: 743-760, doi: 10.5194/tc-8-743-2014.

Han S-C, Shum CK, Bevis M, Ji C, Kuo1 C-Y (2006) Crustal dilatation observed by GRACE after the 2004 Sumatra-Andaman earthquake, Science, 313: 658-662, doi: 10.1126/science.1128661.

Han S-C, Sauber J, Riva REM (2011) Contribution of satellite gravimetry to understanding seismic source processes of the 2011 Tohoku-Oki earthquake, Geophys Res Lett, 38, L24312, doi: 10.1029/2011GL049975.

Jekeli C (1981) Alternative methods to smooth the Earth's gravity field, Technical Report No. 327, Ohio State University, Columbus, Ohio, USA.

Joughin I, Tulaczyk S (2002) Positive mass balance of the Ross ice streams, West Antarctica, Science 295: 476-480, doi: 10.1126/science.1066875.

Kim J (2000) Simulation study of a low-low satellite-to-satellite tracking mission, PhD Thesis, Center for Space Research, The University of Texas at Austin, Texas, USA. 
Klees R, Broersen P (2002) How to handle colored noise in large least-squares problems - Building the optimal filter, Delft University Press, DUP Science, Delft, The Netherlands.

Klees R, Ditmar P, Broersen P (2003) How to handle colored observation noise in large least-squares problems, J Geod, 76: 629-640, doi: 10.1007/s00190-002-0291-4.

Klees R, Ditmar P (2004) How to handle colored noise in large least-squares problems in the presence of data gaps? in Sansò F (ed.), V HotineMarussi Symposium on Mathematical Geodesy, International Association of Geodesy Symposia, vol. 127, pp. 39-48, doi: 10.1007/978-3-662-10735$5 \_6$.

Klees R, Zapreeva EA, Winsemius HC, Savenije HHG (2007) The bias in GRACE estimates of continental water storage variations, Hydrol Earth Syst Sci, 11: 1227-1241, doi: 10.5194/hess-11-1227-2007.

Klees R, Liu X, Wittwer T, Gunter BC, Revtova EA, Tenzer R, Ditmar P, Winsemius HC, Savenije HHG (2008a) A comparison of global and regional GRACE models for land hydrology, Surv Geophys, 29: 335-359, doi: 10.1007/s10712-008-9049-8.

Klees R, Revtova EA, Gunter BC, Ditmar P, Oudman E, Winsemius HC, Savenije HHG (2008b) The design of an optimal filter for monthly GRACE gravity models, Geophys J Int, 175: 417-432, doi: 10.1111/j.1365246X.2008.03922.x. 
Kroes R, Montenbruck O, Bertiger W, Visser P (2005) Precise GRACE baseline determination using GPS, GPS Solut, 9: 21-31, doi: 10.1007/s10291004-0123-5.

Kurtenbach E, Mayer-Gürr T, Eicker A (2009) Deriving daily snapshots of the Earth's gravity field from GRACE L1B data using Kalman filtering, Geophys Res Lett, 36, L17102, doi: 10.1029/2009GL039564.

Kusche J (2007) Approximate decorrelation and non-isotropic smoothing of time-variable GRACE-type gravity field models, J Geod, 81: 733-749, doi: 10.1007/s00190-007-0143-3.

Kusche J, Schmidt R, Petrovic S, Rietbroek R (2009) Decorrelated GRACE time-variable gravity solutions by GFZ, and their validation using a hydrological model, J Geod, 83: 903-913, doi: 10.1007/s00190-009-0308-3.

Lenaerts JTM, van den Broeke MR, van de Berg WJ, van Meijgaard E, Munneke PK (2012) A new, high-resolution surface mass balance map of Antarctica (19792010) based on regional atmospheric climate modeling, Geophys Res Lett, 39, L04501, doi: 10.1029/2011GL050713.

Ligtenberg, SRM, Helsen MM, van den Broeke MR (2011) An improved semiempirical model for the densification of Antarctic firn, The Cryosphere, 5: 809-819, doi: 10.5194/tc-5-809-2011.

Liu X (2008) Global gravity field recovery from satellite-to-satellite tracking data with the acceleration approach, PhD Thesis, Delft University of Technology, Delft, The Netherlands. 
Liu X, Ditmar P, Siemes C, Slobbe DC, Revtova E, Klees R, Riva R, Zhao Q (2010) DEOS Mass Transport model (DMT-1) based on GRACE satellite data: methodology and validation, Geophys J Int, 181: 769-788, doi: 10.1111/j.1365-246X.2010.04533.x.

Luthcke SB, Zwally HJ, Abdalati W, Rowlands DD, Ray RD, Nerem RS, Lemoine FG, McCarthy JJ, Chinn DS (2006) Recent Greenland ice mass loss by drainage system from satellite gravity observations, Science, 314: 1286-1289, doi: 10.1126/science.1130776.

Luthcke SB, Sabaka TJ, Loomis BD, Arendt AA, McCarthy JJ, Camp J (2013) Antarctica, Greenland and Gulf of Alaska land ice evolution from an iterated GRACE global mascon solution, J Glaciol, 59: 613-631, doi: 10.3189/2013JoG12J147.

Mayer-Gürr T (2006) Gravitationsfeldbestimmung aus der Analyse kurzer Bahnbögen am Beispiel der Satellitenmissionen CHAMP und GRACE, PhD Thesis, University of Bonn, Bonn, Germany.

Mayer-Gürr T, Eicker A, Kurtenbach E, Ilk K-H (2010a) ITG-GRACE: Global static and temporal gravity field models from GRACE data, in Flechtner F, Gruber T, Güntner A, Mandea M, Rothacher M, Schöne T, Wickert J (eds.), System Earth via Geodetic-Geophysical Space Techniques, pp. 159-168, doi: 10.1007/978-3-642-10228-8_13.

Mayer-Gürr T, Eicker A, Kurtenbach E (2010b) ITG-Grace2010: The new GRACE gravity field release computed in Bonn, Geophys Res Abs, 12, EGU2010-2446. 
Mayer-Gürr T, Zehentner N, Klinger B, Kvas A (2014) ITSG-Grace2014: a new GRACE gravity field release computed in Graz, in GRACE Science Team Meeting, Potsdam, Germany.

Meyer U, Jäggi A, Beutler G (2012) Monthly gravity field solutions based on GRACE observations generated with the Celestial Mechanics Approach, Earth Planet Sc Lett, 345: 72-80, doi: 10.1016/j.epsl.2012.06.026.

McCarthy DD, Petit G (2004) IERS conventions (2003) IERS Technical Note 32, Verlag des Bundesamtes für Kartographie und Geodäsie, Frankfurt am Main, Germany.

Heiskanen WA, Moritz H (1967) Physical Geodesy, Bull Geodesique, 86: 491, doi: $10.1007 / \mathrm{BF} 02525647$.

Rignot E, Mouginot J (2012) Ice flow in Greenland for the International Polar Year 2008-2009, Geophys Res Lett, 39, L11501, doi: 10.1029/2012GL051634.

Savcenko R, Bosch W (2012) EOT11a - Empirical ocean tide model from multi-mission satellite altimetry, Report No. 89, Deutsches Geodätisches Forschungsinstitut (DGFI), München, Germany.

Siemes C, Ditmar P, Riva REM, Slobbe DC, Liu X, Farahani HH (2013) Estimation of mass change trends in the Earth's system on the basis of GRACE satellite data, with application to Greenland, J Geod, 87: 69-87, doi: 10.1007/s00190-012-0580-5.

Standish EM (1998) JPL planetary and lunar ephemerides, DE405/LE405, Jet Propulsion Labratoary, IOM 312.F - 98 - 048. 
Sun Y, Riva R, Ditmar P (2016) Optimizing estimates of annual variations and trends in geocenter motion and $\mathrm{J} 2$ from a combination of GRACE data and geophysical models, J Geophys Res (in review).

Swenson S, Wahr J, Milly PCD (2003) Estimated accuracies of regional water storage variations inferred from the Gravity Recovery and Climate Experiment (GRACE), Water Resour Res, 39(8), 1223, doi: 10.1029/2002WR001808.

Swenson S, Chambers D, Wahr J (2008) Estimating geocenter variations from a combination of GRACE and ocean model output, J Geophys Res, 113, B08410, doi: 10.1029/2007JB005338.

Tapley BD, Bettadpur S, Watkins M, Reigber C (2004a) The gravity recovery and climate experiment: Mission overview and early results, Geophys Res Lett, 31, L09607, doi: 10.1029/2004GL019920.

Tapley BD, Bettadpur S, Ries JC, Thompson PF, Watkins MM (2004b) GRACE measurements of mass variability in the Earth system, Science, 305: 503-505, doi: 10.1126/science.1099192.

Wahr J, Molenaar M, Bryan F (1998) Time variability of the Earth's gravity field: Hydrological and oceanic effects and their possible detection using GRACE, J Geophys Res, 103(B12): 30205-30229, doi: 10.1029/98JB02844.

van der Wal W, Wu P, Sideris MG, Shum CK (2008) Use of GRACE determined secular gravity rates for glacial isostatic adjustment studies in North-America, J Geodyn, 46: 144-154, doi: 10.1016/j.jog.2008.03.007. 
Watkins MM, Yuan D (2007) JPL level-2 processing standards document for product release 04, GRACE 327-744.

Watkins MM, Yuan D (2012) JPL level-2 processing standards document for product release 05, GRACE 327-744.

Watkins MM, Wiese DN, Yuan D-N, Boening C, Landerer FW (2015) Improved methods for observing Earth's time variable mass distribution with GRACE using spherical cap mascons, J Geophys Res, 120, 2648-2671, doi: 10.1002/2014JB011547.

Whitehouse PL, Bentley MJ, Milne GA, King MA, Thomas ID (2012) A new glacial isostatic adjustment model for Antarctica: calibrated and tested using observations of relative sea-level change and present-day uplift rates, Geophys J Int 190: 1464-1482, doi: 10.1111/j.1365-246X.2012.05557.x.

Wouters B, Chambers D, Schrama EJO (2008) GRACE observes smallscale mass loss in Greenland, Geophys Res Lett, 35, L20501, doi: 10.1029/2008GL034816.

Zhao Q (2004) Research on precise orbit determination theory and software for both GPS navigation constellation and LEO satellites, PhD Thesis, Wuhan University, Wuhan, China. 